CAMP Working Paper Series

No 6/2014

\title{
Boom or gloom? Examining the Dutch disease in two-speed economies
}

Hilde C. Bjørnland and Leif Anders Thorsrud

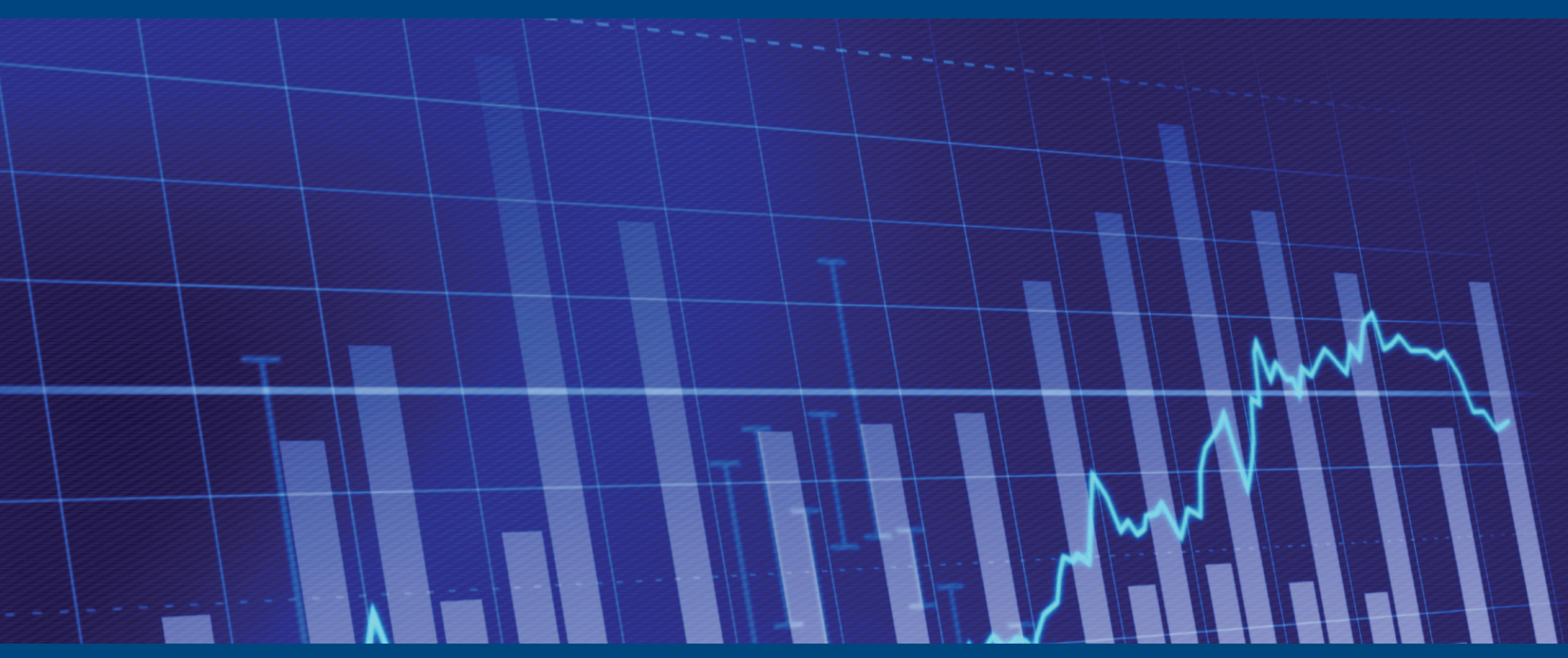

(c) Authors 2014.

This paper can be downloaded without charge from the CAMP website http://www.bi.no/camp 


\title{
Boom or gloom? Examining the Dutch disease in two-speed economies*
}

\author{
Hilde C. Bjørnland ${ }^{\dagger} \quad$ Leif Anders Thorsrud ${ }^{\ddagger}$
}

September 24, 2014

\begin{abstract}
Traditional studies of the Dutch disease do not account for productivity spillovers between the booming resource sector and other domestic sectors. We put forward a simple theory model that allows for such spillovers. We then identify and quantify these spillovers using a Bayesian Dynamic Factor Model (BDFM). The model allows for resource movements and spending effects through a large panel of variables at the sectoral level, while also identifying disturbances to the commodity price, global demand and non-resource activity. Using Australia and Norway as representative cases studies, we find that a booming resource sector has substantial productivity spillovers on non-resource sectors, effects that have not been captured in previous analysis. That withstanding, there is also evidence of two-speed economies, with non-traded industries growing at a faster pace than traded. Furthermore, commodity prices also stimulate the economy, but primarily if an increase is caused by higher global demand. Commodity price growth unrelated to global activity is less favourable, and for Australia, there is evidence of a Dutch disease effect with crowding out of the tradable sectors. As such, our results show the importance of distinguishing between windfall gains due to volume and price changes when analysing the Dutch disease hypothesis.
\end{abstract}

JEL-codes: C32, E32, F41, Q33

Keywords: Resource boom, commodity prices, Dutch disease, learning by doing, two-speed economy, Bayesian Dynamic Factor Model (BDFM)

${ }^{*}$ This is a substantially revised version of CAMP Working Paper 6/2013 with the slightly different title: "Bloom or gloom? Examining the Dutch disease in a two-speed economy". The authors would like to thank the Editor Morten Ravn, two anonymous referees, Francesco Ravazzolo, Ragnar Torvik and Benjamin Wong, as well as seminar and conference participants at the Reserve Bank of New Zealand, Norges Bank, the IAAE 2014 annual conference in London, the CAMP-CAMA Workshop on Commodities and the Macroeconomy at Australia National University, and the CAMP Workshop on Commodity Price Dynamics and Financialization in Oslo for valuable comments. Bjørnland and Thorsrud acknowledge financial support from the Norwegian Financial Market Fund under the Norwegian Research Council and the Centre for Applied Macro and Petroleum economics (CAMP) at the BI Norwegian Business School. The views expressed are those of the authors and do not necessarily reflect those of Norges Bank. The usual disclaimers apply.

${ }^{\dagger}$ Centre for Applied Macro and Petroleum economics, BI Norwegian Business School, and Norges Bank. Email: hilde.c.bjornland@bi.no

${ }^{\ddagger}$ Centre for Applied Macro and Petroleum economics, BI Norwegian Business School. Email: leif.a.thorsrud@bi.no 


\section{Introduction}

Over the last decade, commodity producers such as Australia and Norway have experienced growth rates exceeding those of comparable advanced economies by up to 0.5 percentage points on a yearly basis. A boom in the extraction of natural resources is important in explaining this growth performance. In particular, the value of the Norwegian oil and gas industry - including services - grew by approximately 90 percent, while employment in this industry grew by more than 60 percent. No other industry exhibited such growth rates. Even more pronounced was the development that played out in the mineral abundant country, Australia. The value of mining increased by 130 percent, while employment in the same industry went up by 105 percent.

The mineral boom in Australia and the oil and gas boom in the North Sea have been the principal, but far from only, cause of the substantial growth enjoyed by both these countries. A strong rise in commodity prices has caused Australia and Norway's terms of trade to almost double since 2003. These price rises have profound effects on economies, as they constitute both a large increase in real income, boosting aggregate demand in the wider economy, but also a large shift in relative prices, inducing resource movements between industries. For instance, while employment in the non-tradable sectors such as construction and business service in both Australia and Norway increased by 30-40 percent over the last decade, employment in sectors such as manufacturing, and the hotel and service industry, has either fallen or at best, hardly grown. This has prompted much discussion as to whether Australia and Norway might have become two-speed economies, see e.g. Garton (2008). There are concerns that the gains from the boom largely accrue to the profitable sectors servicing the resource industry, while the rest of the country is suffering adverse effects from increased wage costs, an appreciated exchange rate and a lack of competitiveness as a result of the boom. In the literature, such a phenomenon has commonly been referred to as the Dutch disease, based on similar experiences in the Netherlands in the 1960s. ${ }^{1}$

Figure 1 below summarizes these concerns for the two resource-rich economies: a two-speed development in the labour market coupled with an appreciating exchange rate alongside soaring commodity prices.

Much theoretical work has been done on analysing the benefits and costs of resource discoveries, see for instance Bruno and Sachs (1982), Corden and Neary (1982), Eastwood and Venables (1982), Corden (1984), van Wijnbergen (1984) and Neary and van Wijnbergen (1984) for early contributions. There have, however, been relatively few empirical studies. In addition, the standard Dutch disease model on which these papers are based typically does not account for productivity spillovers between the resource rich sector and the rest of the economy. Experience in Australia, and Norway in particular, suggests that this could be important. For instance, as the development of offshore oil often demands complicated technical solutions, this could in itself generate positive knowledge externalities that benefit other sectors. And since these sectors trade with other industries in the

\footnotetext{
${ }^{1}$ Following the discovery and development of natural gas industries in the 1960s, the Netherlands experienced a period of real exchange rate appreciation and a corresponding loss of competitiveness and eventual contraction of traditional industries.
} 
Figure 1. Boom or gloom? Stylized facts

Norway
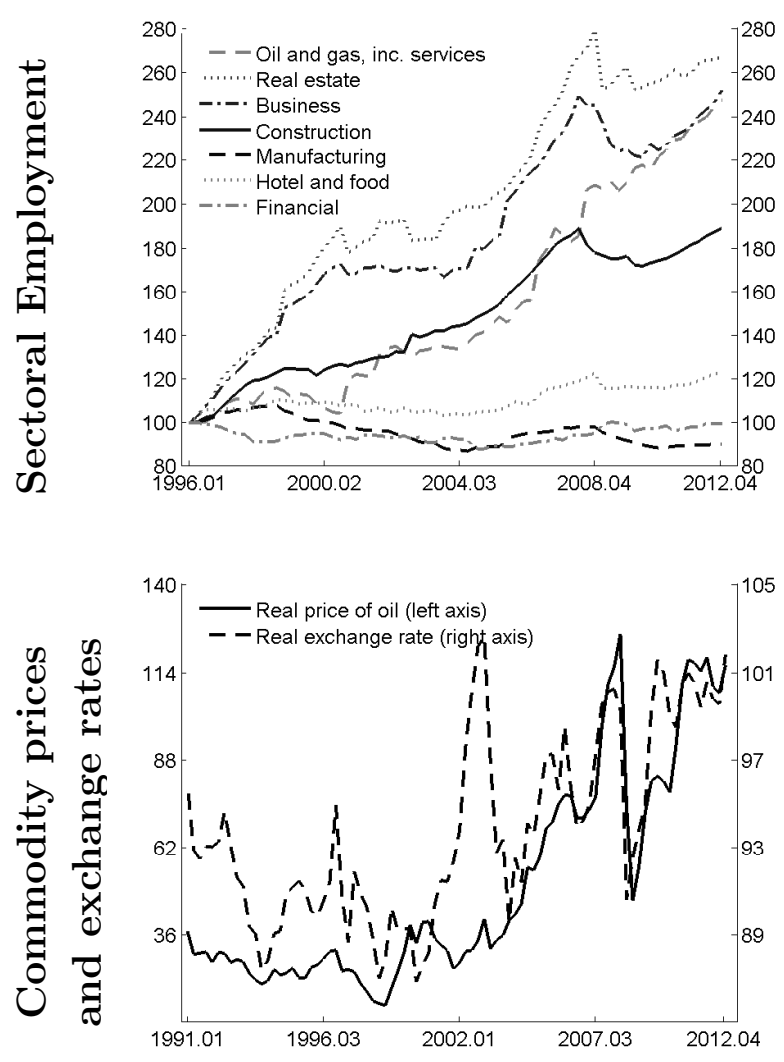

Australia
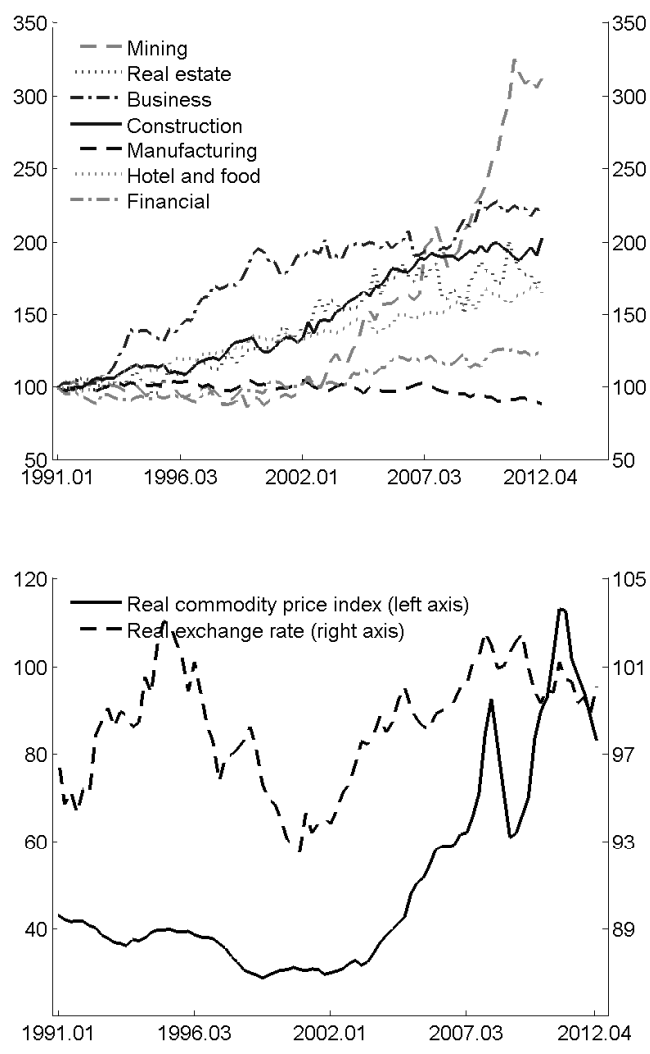

Note: The employment series are on a log scale, normalized to 100 in 1991:Q1 (Australia) and 1996:Q1 (Norway. Shorter sample due to data availability). We use the real effective exchange rate, where an increase implies appreciation

economy, there may be learning by doing spillovers to the overall economy. This could be an important explanation for the high growth rates observed in the domestic economies.

To address these issues, we put forward a simple theory model that allows for direct productivity spillovers from the resource sector to both the traded and non-traded sector. We further assume there is learning by doing (LBD) in the traded and non-traded sectors, as well as learning spillovers between these sectors. While the introduction of the direct productivity spillover is new to this paper, the LBD mechanism is similar to that developed in Torvik (2001). Hence, we extend the model of Torvik (2001) with technology spillovers from the resource sector. To the extent that the natural resource sector crowds in productivity in the other sectors, the growth rate in the overall economy will increase.

We test the predictions from our suggested theoretical model against data by estimating a Bayesian Dynamic Factor Model (BDFM) that includes separate activity factors for the resource and non-resource (domestic) sectors in addition to global activity and the real commodity price. Our main focus is to separately examine the windfall gains associated with resource booms and commodity price changes, while also allowing global demand to affect commodity prices, see i.e., Hamilton (1983, 2009), Barsky and Kilian 
(2002) and Kilian (2009) for discussions on this latter feature. ${ }^{2}$

The BDFM is particularly useful to answer the research questions we address. First, the interdependence between the different branches of an economy - traditionally measured by the input-output tables from the National Accounts - do not account for the indirect spillover effects (productivity or demand) between different sectors. Thus, co-movement across sectors, e.g., oil or non-oil, due to common factors, is not captured by observable variables alone. Conversely, in the BDFM, latent common factors can be identified and estimated simultaneously with the rest of the model's parameters. Thus, the size and sign of spillover effects can be derived and analysed. Second, to quantify the spillover effects across a large cross section of sectors and variables, standard multivariate time series techniques are inappropriate due to the curse of dimensionality. The BDFM is designed for data rich environments such as ours. Third, macroeconomic data are often measured with noise and errors. In the factor model framework, we can separate these idiosyncratic noise components from the underlying economic signal.

The empirical analysis is applied to Norway and Australia, two small net exporters of respectively petroleum and minerals. What matters, however, is not their absolute size in the commodity market, but the size of the resource sector relative to the rest of the economy. In particular, in the last decade, more than 75 percent of the value of their export was commodity based, while gross value added in the resource sector took up around 10 and 20 percent of output in Australia and Norway respectively. Thus, the analysis could be applied to any commodity-exporting small open economy, as long as the resource sector represents a relatively important share of the overall economy.

We extend the literature in three ways. First, to the best of our knowledge, this is the first paper to explicitly analyse and quantify the linkages between a booming energy sector and sectoral performance in the domestic economy using a structural model, while also allowing for explicit disturbances in real commodity prices, world activity and activity in the domestic sector. So far there have been very few studies empirically examining the relationship between a booming resource sector and the rest of the economy. Those that have analysed the issue, have typically employed a structural vector autoregression (SVAR), including only a single sector in the non-resource economy, typically manufacturing or domestic output, see, e.g., Hutchison (1994), Bjørnland (1998) and Dungey et al. (2014), or a panel data approach studying common movements in manufacturing across numerous countries, see, e.g., Ismail (2010). The overall conclusion has typically been that effects of, say, mining or petroleum investment on domestic output are small, c.f., Dungey et al. (2014) or Bjørnland (1998). However, neither of these approaches accounts for all of the cross-sectional co-movement of variables within a country. The BDFM does.

A related study in that regard, is presented in a recent paper by Charnavoki and Dolado (2014). They examine how changes in commodity prices affect the commodityexporter Canada, and uncover a Dutch disease effect using a structural factor model. However, as alluded to above, a windfall gain due to a change in commodity prices is only one channel through which resource wealth can affect the domestic economy. Alterna-

\footnotetext{
${ }^{2}$ This is important. Table 4 in Appendix B shows that GDP growth and growth in the manufacturing industry are positively correlated with the commodity price. However, this positive correlation could easily just be the result of higher global demand, not evidence against any Dutch disease pattern in itself.
} 
tively, a resource boom could be caused by (unpredicted) technical improvements in the booming sector, represented by a favourable shift in the production function, or, say, a windfall discovery of new resources, see e.g. Corden (1984) for details. In Charnavoki and Dolado (2014) this channel is not investigated. We claim that it might be important.

Second, given the large number of variables and industries included in the analysis, this is also the most comprehensive analysis to date of the relationship between resource booms and activity at the industry level in resource rich economies. Lastly, the use of the BDFM modelling framework to analyse the Dutch disease is novel in the literature. ${ }^{3}$

Our main conclusion emphasizes that a booming resource sector has significant and positive productivity spillovers on non-resource sectors, effects that have not been captured by previous analyses. In particular, we find that the resource sector stimulates productivity and production in both Australia and Norway. What is more, value added and employment both increase in the non-traded relative to the traded sectors, suggesting a two-speed transmission phase. The most positively affected sectors are construction, business services, and real estate.

Further to this, windfall gains derived from changes in the commodity price also stimulate the economy, particularly if the rise in commodity price is associated with a boom in global demand. However, commodity price increases unrelated to global activity are less favourable, in part because of substantial real exchange rate appreciation and reduced competitiveness. Still, value added and employment rise temporarily in Norway, mostly due to increased activity in the technologically intense service sectors and the boost in government spending. For Australia, the picture is more gloomy, as there is evidence of a Dutch disease effect with crowding out and an eventual decline in manufacturing.

These results emphasize the importance of distinguishing between windfall gains due to volume and price changes when analysing the Dutch disease hypothesis. To the best of our knowledge, this is the first paper to explicitly separate and quantify these two channels, while also allowing for explicit disturbances to global activity and the nonresource sectors.

The remainder of the paper is structured as follows. In Section 2, we discuss the theoretical literature on Dutch disease and develop a simple alternative theoretical model. Section 3 details the data and the model, the identification strategy, and the estimation procedure used in the empirical investigation. Our main results are reported in Section 4, while in Section 5 we describe how these results are robust to numerous specification tests. Section 6 concludes.

\section{The model}

The traditional literature on the Dutch disease typically predicts an inverse long run relationship between the exploitation of natural resources and the development in the traded sector (i.e., manufacturing), see Corden (1984) for an overview of the literature.

${ }^{3}$ Charnavoki and Dolado (2014) also estimate the parameters of their factor model using Bayesian methods. However, in contrast to their approach, our model yields unique identification of the shocks and factors. We also take into account uncertainty regarding the unobserved factors. 
The negative effect comes about from a movement of resources out of the traded and nontraded sector and into the booming sector that extracts the natural resource (Resource Movement Effect). There will also be indirect (secondary) effects of increased demand by the sectors that produce goods and services for the booming sector (Spending Effect). This will cause a real appreciation that will hurt the traded sectors.

A limitation of the traditional Dutch disease literature is that is assumes productivity to be exogenous to the model. However, in some resource-rich countries, the exploitation of natural resources could have substantial productivity spillovers to the other sectors in the economy. For example, as the development of offshore oil often demands complicated technical solutions, this could in itself generate positive knowledge externalities that benefit some sectors. If these sectors trade with other industries in the economy, then there are likely to be learning-by-doing spillovers to the overall economy.

To account for these features, we develop a model that allows for direct productivity spillovers from the natural resource sector to both the traded and non-traded sector. In addition, we assume there is learning by doing (LBD) in the traded and non-traded sectors, as well as learning spillovers between these sectors. While the introduction of the direct productivity spillover is new to this paper, the LBD mechanism is similar to that developed in Torvik (2001). In particular, Torvik (2001) assumes that both the traded and the non-traded sector can contribute to learning and that there are spillovers between these sectors. Hence, we extend the model of Torvik (2001) with technology spillovers from the resource sector. In doing so, we show that if the natural resource sector crowds in productivity in the other sectors, the growth rate in the overall economy will increase.

To focus on the new mechanisms, the following assumptions are made: there is no unemployment; the natural resource boom is exogenous (i.e., a foreign exchange gift); there is balanced trade; labour is the only production factor; and labour mobility between sectors is perfect.

The resource boom is denoted $R_{t}$, and is measured in terms of traded sector productivity units. ${ }^{4}$ In line with Corden (1984), we assume that an increase in $R_{t}$ can be thought of as happening in one of three ways. (i) An (unpredicted) technical improvement in the booming sector, represented by a favourable shift in the production function; (ii) a windfall discovery of new resources; or, (iii) an exogenous rise in the world real price of the resource that is exported. In line with the literature, we consider case (i) or (ii) in the analysis below. In the empirical analysis we will, however, also allow for a windfall gain due to an increase in the real prices of the natural resources (i.e., case (iii)).

We denote production at time $t$ in the non-traded and traded sectors as $X_{N t}$ and $X_{T t}$, respectively. The total labour force is normalised to one, and $\eta_{t}$ denotes the labour force employed in the non-traded sector. The traded and the non-traded sectors have production functions $X_{N t}=H_{N t} f\left(\eta_{t}\right)$ and $X_{T t}=H_{T t} g\left(1-\eta_{t}\right)$ respectively, where $H_{N t}$ and $H_{T t}$ are the respective sectoral productivities for the non-traded and the traded sectors. We assume diminishing returns to labour in each sector and the productivity parameters enter with constant returns to scale, as is standard in the endogenous growth literature with one factor of production, see Torvik (2001). Total income in the economy

\footnotetext{
4 To ensure that the (flow of the) foreign exchange gift does not die out as a share of income, we assume that it grows over time.
} 
(measured in traded goods), $Y_{t}$, will now be the value of production in the non-traded and traded sectors, plus the value of the foreign exchange gift: $Y_{t}=P_{t} X_{N t}+X_{T t}+H_{T t} R_{t}$, where $P_{t}$ is the price of the non-traded goods in terms of traded goods, i.e., the real exchange rate. Finally, we assume productivity in the traded and non-traded sectors to have the following growth rates:

$$
\begin{aligned}
& \frac{\dot{H}_{N t}}{H_{N t}}=u \eta\left(\lambda_{t}, R_{t}\right)+v \delta_{T}\left(1-\eta\left(\lambda_{t}, R_{t}\right)\right)+\delta_{R} R_{t}, \quad 0 \leq \delta_{T} \leq 1 \\
& \frac{\dot{H}_{T t}}{H_{T t}}=u \delta_{N} \eta\left(\lambda_{t}, R_{t}\right)+v\left(1-\eta\left(\lambda_{t}, R_{t}\right)\right)+\delta_{R} R_{t}, \quad 0 \leq \delta_{N} \leq 1
\end{aligned}
$$

where a "dot" above a variable indicates the derivative of the variable with respect to time. One unit of labour use in the non-traded (traded) sector contributes a productivity growth rate of $u(v)$ in the non-traded (traded) sector. Further, a fraction $\delta_{T}\left(\delta_{N}\right)$ of the learning from employment in the traded (non-traded) sector spills over to the non-traded (traded) sector. Finally, we allow for a direct LBD spillover from the resource to domestic sector. Resource extraction implies learning, and we assume the spillover to domestic sectors is governed by the learning parameter $\delta_{R} \geqslant 0$. It is reasonable to assume that the more technologically advanced the resource sector, the higher the $\delta_{R}$.

The relative productivity level between the two sectors is defined as $\lambda_{t}=H_{T t} / H_{N t}$, thus:

$$
\frac{\dot{\lambda}_{t}}{\lambda_{t}}=\frac{\dot{H}_{T t}}{H_{T t}}-\frac{\dot{H}_{N t}}{H_{N t}}
$$

Importantly, we see from equations (1) and (2) that the growth in productivity is assumed to be endogenous, as it depends on the labour share and the resource boom. We also see that the introduction of the direct technology spillover will not affect relative productivity, as long as it is assumed to affect productivity in each sector equally as we do here.

We assume consumers allocate spending on non-traded and traded goods according to a utility function with constant elasticity of substitution, $\sigma$. Total income is given by the value of production in the non-traded and traded sector, plus the value of the foreign exchange gift. In equilibrium, demand must equal supply of non-traded goods. We can then characterize the real exchange rate as a function of the employment share in the non-traded sector, the relative productivity level and the resource boom (see Torvik (2001) for derivations):

$$
P_{t}=\lambda_{t}^{1 / \sigma}\left[\frac{g\left(1-\eta_{t}\right)+R_{t}}{f\left(\eta_{t}\right)}\right]^{1 / \sigma}
$$

Furthermore, equilibrium in the labour market requires the value of the marginal productivity of labour in the two sectors to be equal: $P_{t} H_{N t} f^{\prime}\left(\eta_{t}\right)=H_{T t} g^{\prime}\left(1-\eta_{t}\right)$, thus:

$$
P_{t}=\lambda_{t} \frac{g^{\prime}\left(1-\eta_{t}\right)}{f^{\prime}\left(\eta_{t}\right)}
$$

Figure 2 displays the relationship between the real exchange rate and the employment share in the non-traded sector for given values of the foreign exchange gift and sectoral productivities. Equation 4 is drawn as the downward sloping NN curve. It reflects the 
Figure 2. Resource boom shock and LBD dynamics

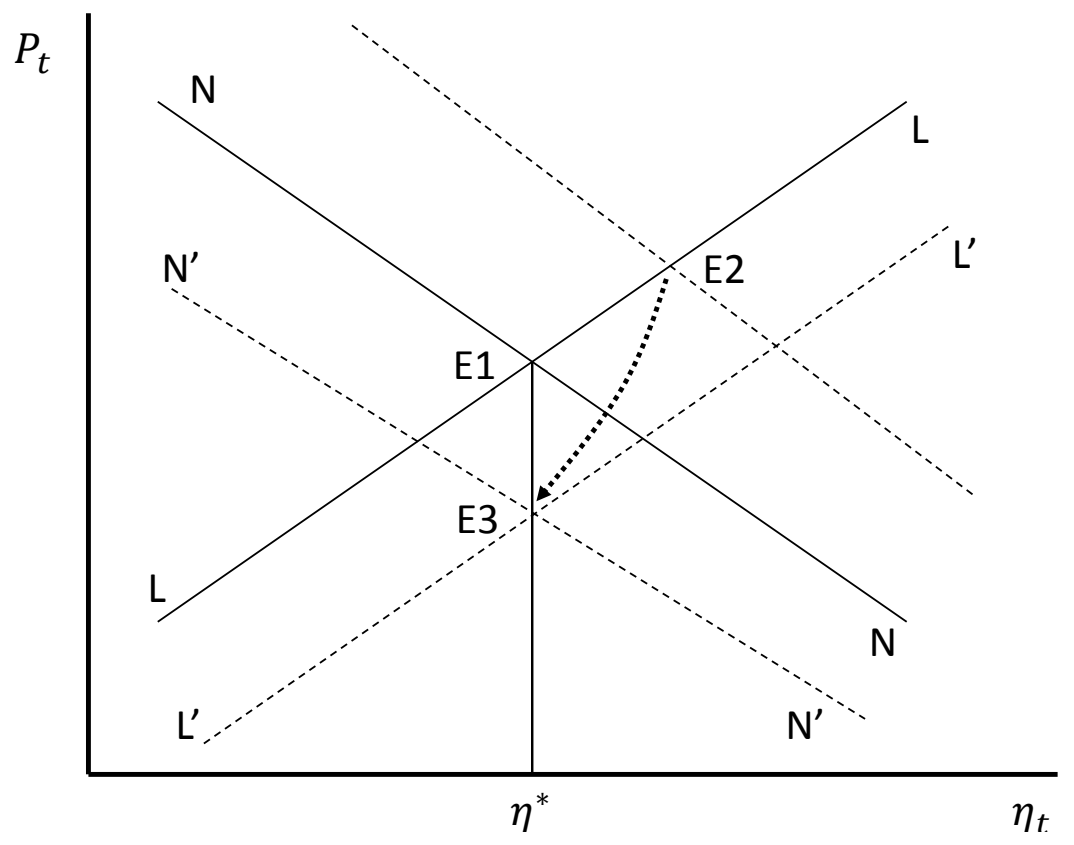

non-traded market equilibrium when expenditure is always equal to income. ${ }^{5}$ Equation 5 is drawn as the upward sloping LL curve. It reflects the labour market equilibrium. ${ }^{6}$ The (static) equilibrium between the real exchange rate and the labour share is given by the intersection of the two curves, at point E1. Assuming this is a steady state, the growth rates in the productivities must be equal, so that (equating equations (1) and (2)):

$$
\eta^{*}=\frac{v\left(1-\delta_{T}\right)}{u\left(1-\delta_{N}\right)+v\left(1-\delta_{T}\right)}
$$

We can now study the effect of a resource gift. An exogenous shock to $R_{t}$ causes the NN curve to shift up. At the new intersection, E2, the exchange rate has appreciated, and the amount of labour used in the non-traded sector has increased. This is what is commonly referred to as the Dutch disease effects. However, since the growth rates of the productivities are endogenous in this model, the relative productivity level $\lambda_{t}$ between the two sectors also changes:

$$
\frac{\dot{\lambda}_{t}}{\lambda_{t}}=-u\left(1-\delta_{T}\right) \eta\left(\lambda_{t}, R_{t}\right)+v\left(1-\delta_{T}\right)\left[1-\eta\left(\lambda_{t}, R_{t}\right)\right]
$$

The derivative of equation (7) with respect to $R_{t}$ is equal to:

$$
\frac{d\left(\dot{\lambda}_{t} / \lambda_{t}\right)}{d R_{t}}=-\left[u\left(1-\delta_{T}\right)+v\left(1-\delta_{T}\right)\right] \frac{d \eta\left(\lambda_{t}, R_{t}\right)}{d R_{t}}<0
$$

\footnotetext{
${ }^{5}$ If $\eta_{t}$ increases, there will be an excess supply of non traded goods, and $P_{t}$ has to fall (a real exchange rate depreciation) to restore balance by shifting demand from traded to non-traded goods.

${ }^{6} \mathrm{An}$ increase in the value of $P_{t}$ causes the marginal productivity of labour in the non-traded sector to become higher than in the traded sector. To re-establish the equality between the value of the marginal productivity of labour in the two sectors at the new exchange rate, labour use in the non-traded sector has to increase.
} 
Thus, an exogenous increase in $R_{t}$ not only shifts the NN curve up, it also causes the productivity gap between the traded and non-traded sector to diminish over time. ${ }^{7}$ A fall in $\lambda$ causes the LL and NN curves to shift down over time. This is depicted by the curves N'N' and L'L' in Figure 2. The new (dynamic) equilibrium is reached at point E3, where the real exchange rate has actually depreciated. The intuition is as follows: After the initial resource boom more people are employed in the non-tradable sector, which therefore experiences higher productivity growth. This in turns narrows the productivity gap between the two sectors, and shifts the NN and LL curves down over time. Labour is pushed out of the sector with the fastest productivity growth. This process will continue until the labour share is back at its original value. In the new steadystate, relative production of the two sectors will have shifted in favour of the non-traded sector as is conventional in models of the Dutch disease. However, this is not because of new factor allocations, but of a shift in the steady-state relative productivity between the two sectors. ${ }^{8}$

As in Torvik (2001), the steady-state labour share between the two sectors does not change after an exogenous shock to $R_{t}$. However, equilibrium output (productivity) growth will now be directly affected. To see this, insert the steady-state labour share in Equation (6) into one of the two equations for sectoral productivity growth. The steady state growth rate, denoted $g^{*}$, is then given by:

$$
g^{*}=\delta_{R} R+\frac{v\left(1-\delta_{T}\right)}{u\left(1-\delta_{N}\right)+v\left(1-\delta_{T}\right)}
$$

At this point, the rate of growth in the economy will be a direct function of the spillover from the resource gift. The effect depends on the size of the spillover. If $\delta_{R}>0$, the resource gift crowds in productivity in the traded and non-traded sectors. Hence, output (and productivity) growth in both sectors increases, which is contrary to standard Dutch disease models. This is a new feature of our model.

In addition, there is a secondary effect due to the spillovers between the traded and the non-traded sectors. This mechanism is similar to the one described in Torvik (2001). The direction of this shift depends on the parameters $u, v, \delta_{T}$ and $\delta_{N}$, which describe the direct and indirect spillovers on the productivity growth in the two sectors. In particular, if the indirect effect $\left(\delta_{N}\right)$ dominates in the traded sector while the direct effect $(u)$ dominates in the non-traded sector, output (productivity) growth in both sectors will increase. ${ }^{9}$

To sum up, our model has two implications for the dynamic adjustment after a resource boom. First, when the resource boom crowds in productivity spillovers in the

\footnotetext{
${ }^{7}$ Note that relative productivity is not affected by the direct productivity spillovers, $\delta_{R}$. Hence, expressions (7) and (8) are similar to equations (13) and (14) in Torvik (2001). He shows that when the elasticity of substitution $\sigma$ is less than one, the model has a stable interior solution.

${ }^{8}$ As a results of the same shift, and because a change in $R_{t}$ does not affect $\eta^{*}$, the real exchange rate also has to depreciate, see Torvik (2001) for a formal proof.

${ }^{9}$ Earlier studies of the implication of LBD for Dutch disease, i.e., van Wijnbergen (1984) and Krugman (1987), find unambiguously that productivity will decline. The agreement rests upon the assumption that LBD is only generated in the traded sector. Since the foreign exchange gift decreases the size of the traded sector, productivity is reduced. In our set up, this is equivalent to assuming $u=\delta_{T}=\delta_{N}=\delta_{R}=0$, so that equations 1 and 2 reduce to $\frac{H_{N t}^{\prime}}{H_{N t}}=0$ and $\frac{H_{T t}}{H_{T t}}=v\left(1-\eta_{t}\right)$ respectively.
} 
non-resource sectors, productivity (and production) in the overall economy will increase. Second, learning-by-doing spillovers between the traded and non-traded sectors may enforce this mechanism, by allowing productivity in the non-traded sector to increase relative to the traded sector. Hence, we could expect to see a two-speed adjustment in the process, with the non-traded sectors growing at a faster pace than the traded sector.

\section{Theory meets empirical model}

To investigate the empirical relevance of the theory model, and to answer our main research questions, we specify a Dynamic Factor Model (DFM). Here the co-movement of a large cross section of variables can be represented more parsimoniously than with standard time series techniques, and the direct and indirect spillovers between the different sectors of the economy can be estimated simultaneously. ${ }^{10}$

In line with the theory model, the DFM includes four factors with associated shocks that have the potential to affect all sectors of the economy. Two shocks will be related directly to the Dutch disease literature: a resource boom/activity shock and a commodity price shock (we use the terms resource booms and resource activity shocks interchangeably). Here, the former is similar to the exogenous shocks to $R_{t}$ from the theory model in the previous section, while the latter is what is commonly used in the empirical (time series) literature on Dutch disease. We postulate that it is important to distinguish between these two shocks, as only the $R_{t}$ shock can plausibly lead to strong learningby-doing spillovers (as described above) between the sectors. In addition, we allow for a global activity shock and domestic (non-resource) activity shock. The global activity shock controls for higher economic activity driven by international developments. Importantly, the global shock also allows for higher commodity prices due to increased global demand for commodities. As such, the commodity price shocks themselves should be interpreted as shocks unrelated to global activity, that can change the commodity price on impact. Lastly, the domestic activity shock controls for the remaining domestic impulses (tradable and non-tradable) contemporaneously unrelated to the resource sector. ${ }^{11}$

The factors and shocks will be linearly related to a large panel of domestic variables, including both tradable and non-tradable sectors of the economy. The simple theory model proposed in the previous section makes a clear distinction between these sectors. In the data, this distinction is less clear. However, within the DFM framework the sectors of the economy that are more exposed to foreign business cycle developments, i.e., the tradable sectors, will be endogenously determined through their exposure to the global factor(s) and shocks. Moreover, the direct and indirect spillovers between sectors related to resource extraction and those that are not will be caught up by the dynamic relationship between the resource activity factor and the domestic activity factor, and through the different sectors' exposure to these factors, respectively. These are additional

\footnotetext{
${ }^{10}$ Geweke (1977) is an early example of the use of the DFM in the economic literature. Kose et al. (2003) and Mumtaz et al. (2011) are more recent examples, while Stock and Watson (2005) provide a brief overview of the use of this type of models in economics.

${ }^{11}$ Note that our aim is to control for aggregate domestic impulses, not to identify monetary or say, fiscal policy explicitly.
} 
advantages with our empirical strategy. We do not need to make ad-hoc classifications of the sectors, but are still able to model the direct and indirect spillovers between sectors of the economy in a consistent manner. ${ }^{12}$

Generally, within the DFM framework, the factors are latent. In our application two of the factors are treated as observables, namely global activity and the real commodity price. The two domestic factors are treated as unobservable and have to be estimated based on the available data. For the same reason as above, this allows us to endogenously capture the direct and indirect spillovers between the resource and non-resource driven parts of the economy in a consistent manner.

On a final note, while the theory model focuses on a windfall discovery due to, say, a permanent increase in the production possibilities in the resource sector (an increase in $R_{t}$ ), the windfall discovery in the empirical model will be temporary, but can potentially be very persistent. This is in line with the empirical model framework adopted, where the focus is on the development at the business cycle frequencies. It is also in line with experiences in the two resource rich countries analysed here, where there have been several periods of booms and busts in the resource sectors, as new fields and production possibilities have developed and declined.

\subsection{The Dynamic Factor Model}

We specify one Dynamic Factor Model (DFM) for each of the countries we study: Australia and Norway. In state space form, the DFM is given by equations 10 and 11:

$$
\begin{gathered}
y_{t}=\lambda_{0} f_{t}+\cdots+\lambda_{s} f_{t-s}+\epsilon_{t} \\
f_{t}=\phi_{1} f_{t-1}+\cdots+\phi_{h} f_{t-h}+u_{t}
\end{gathered}
$$

where the $N \times 1$ vector $y_{t}$ represents the observables at time $t . \quad \lambda_{j}$ is a $N \times q$ matrix with dynamic factor loadings for $j=0,1, \cdots, s$, and $s$ denotes the number of lags used for the dynamic factors $f_{t}$. In our application the $q \times 1$ vector $f_{t}$ contains both latent and observable factors. $\epsilon_{t}$ is an $N \times 1$ vector of idiosyncratic errors. Lastly, the dynamic factors follow a $\operatorname{VAR}(\mathrm{h})$ process, given by equation 11 , where, $u_{t}$ is a $q \times 1$ vector of $\operatorname{VAR}(\mathrm{h})$ residuals.

The idiosyncratic and $\operatorname{VAR}(\mathrm{h})$ residuals are assumed to be independent:

$$
\left[\begin{array}{l}
\epsilon_{t} \\
u_{t}
\end{array}\right] \sim \text { i.i.d.N }\left(\left[\begin{array}{l}
0 \\
0
\end{array}\right],\left[\begin{array}{cc}
R & 0 \\
0 & Q
\end{array}\right]\right)
$$

Further, in our application $R$ is assumed to be diagonal. The model described above can easily be extended to the case with serially correlated idiosyncratic errors. In particular, we consider the case where $\epsilon_{t, i}$, for $i=1, \cdots, N$, follows independent $\operatorname{AR}(\mathrm{l})$ processes:

$$
\epsilon_{t, i}=\rho_{1, i} \epsilon_{t-1, i}+\cdots+\rho_{l, i} \epsilon_{t-l, i}+\omega_{t, i}
$$

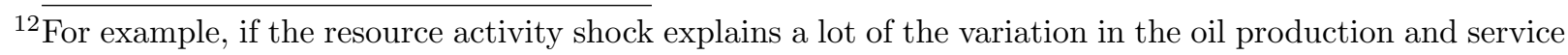
sector in Norway, any sector that supplies a lot of intermediates to this sector is likely to also be affected by the resource activity shock. In particular, to produce output, the oil sector demands supply of goods and services from the other sectors in the economy. As such, any disturbances in the oil producing sector will automatically affect the suppliers. 
where $l$ denotes the number of lags, and $\omega_{t, i}$ is the $\mathrm{AR}(\mathrm{l})$ residuals with $\omega_{t, i} \sim i . i . d . N\left(0, \sigma_{i}^{2}\right)$. I.e.:

$$
R=\left[\begin{array}{cccc}
\sigma_{1}^{2} & 0 & \cdots & 0 \\
0 & \sigma_{2}^{2} & \ddots & 0 \\
\vdots & \ddots & \ddots & \vdots \\
0 & \cdots & \cdots & \sigma_{N}^{2}
\end{array}\right]
$$

\subsection{Identification}

As is common for all factor models, equations 10 and 11 are not identified without restrictions. To separately identify the factors and the loadings, and to be able to provide an economic interpretation of the factors, we enforce the following identification restrictions on equation 10:

$$
\lambda_{0}=\left[\begin{array}{l}
\lambda_{0,1} \\
\lambda_{0,2}
\end{array}\right]
$$

where $\lambda_{0,1}$ is a $q \times q$ identity matrix, and $\lambda_{0,2}$ is left unrestricted. As shown in Bai and $\mathrm{Ng}$ (2013) and Bai and Wang (2012), these restrictions uniquely identify the dynamic factors and the loadings, but leave the $\operatorname{VAR}(\mathrm{h})$ dynamics for the factors completely unrestricted. Accordingly, the innovations to the factors, $u_{t}$, can be linked to structural shocks that are implied by economic theory.

In our application, we set $q=4$ and identify four factors: global activity; the real commodity price; resource specific activity; and non-resource activity. The number of factors and names are motivated by the model as discussed above. ${ }^{13}$ Of these four factors, the first two are observable and naturally load with one on the corresponding element in the $y_{t}$ vector. The two latter must be inferred from the data. For Australia and Norway we require that the resource specific activity factor loads with one on value added in the mining industry and value added in the petroleum sector, respectively. Likewise, the non-resource activity factor loads with one on total value added excluding mining and petroleum in Australia and Norway, respectively. ${ }^{14}$ Note that while these restrictions identify the factors, that does not mean that the factors and the observables are identical as we use the full information set (the vector $y_{t}$ ) to extract the factors.

Based on a minimal set of restrictions, we identify four structural shocks: a global activity shock, a commodity price shock, a resource activity shock (resource booms) and a non-resource (domestic) activity shock. The shocks are identified by imposing a recursive ordering of the latent factors in the model, i.e., $f_{t}=\left[f_{t}^{\text {gact }}, f_{t}^{\text {comp }}, f_{t}^{\text {ract }}, f_{t}^{\text {dact }}\right]^{\prime}$, such that $Q=A_{0} A_{0}^{\prime}$. Specifically, the mapping between the reduced form residuals $u_{t}$ and structural disturbances $e_{t}, u_{t}=A_{0} e_{t}$, is given by:

$$
\left[\begin{array}{c}
u_{t}^{\text {gact }} \\
u_{t}^{\text {comp }} \\
u_{t}^{\text {ract }} \\
u_{t}^{\text {dact }}
\end{array}\right]=\left[\begin{array}{cccc}
a_{11} & 0 & 0 & 0 \\
a_{21} & a_{22} & 0 & 0 \\
a_{31} & a_{32} & a_{33} & 0 \\
a_{41} & a_{42} & a_{43} & a_{44}
\end{array}\right]\left[\begin{array}{c}
e_{t}^{\text {gact }} \\
e_{t}^{\text {comp }} \\
e_{t}^{\text {ract }} \\
e_{t}^{\text {dact }}
\end{array}\right]
$$

\footnotetext{
${ }_{13}$ Moreover, as shown in Appendix C.1, four factors also explain a large fraction of the variance in the data.

${ }^{14}$ Australia has a rich resource sector that produces many different commodities. However, the iron ore sector is by far the largest, and is therefore used to identify the resource boom factor and shocks.
} 
where $e_{t}^{i}$ are the structural disturbances for $i=$ [gact, comp, ract, dact], with $e_{t} e_{t}^{\prime}=I$, and [gact, comp, ract, dact] denote global activity, commodity price, resource activity and domestic activity, respectively.

We follow the usual assumption from both theoretical and empirical models of the commodity market, and restrict global activity to respond to commodity price disturbances with a lag. This restriction is consistent with the sluggish behaviour of global economic activity after each of the major oil price increases in recent decades, see e.g., Hamilton (2009). Furthermore, we do not treat commodity prices as exogenous to the rest of the macro economy. Any unexpected news regarding global activity is assumed to affect real commodity prices contemporaneously. This is consistent with recent work in the oil market literature, see, e.g., Kilian (2009), Lippi and Nobili (2012), and Aastveit et al. (2014). In contrast to these papers, and to keep our empirical model as parsimonious as possible, we do not explicitly identify a global commodity supply shock. ${ }^{15}$ Still, in Appendix C.4, we show that our results are robust to the inclusion of such a shock.

In the very short run, disturbances originating in either the Australian or the Norwegian economy can not affect global activity and real commodity price. These are plausible assumptions, as Australia and Norway are small, open economies. However, both the resource and the domestic activity factors respond to unexpected disturbances in global activity and the real commodity price on impact. In small open economies such as Australia and Norway, news regarding global activity will affect variables such as the exchange rate, the interest rate, asset prices, and consumer sentiments contemporaneously, and thereby affect overall demand in the economy. Australia and Norway are also, respectively, net mineral and oil exporters. Thus, any disturbances to the real commodity price will most likely rapidly affect both the demand and supply side of the economy.

Lastly, in the short run and as predicted by the theory model above, the domestic factor can have no effect on the resource activity factor at time $t$ (it is predetermined), but resource activity shocks can have an effect on the other sectors of the economy contemporaneously (for instance via productivity spillovers). However, at longer horizons it is plausible to assume that, e.g., capacity constraints in the domestic economy eventually also affect the resource sector. Thus, after one period we allow the resource sector to respond to the dynamics in the domestic activity factor. This restriction slightly relaxes the assumptions implied by the theory model.

We emphasize that all observable variables in the model, apart from the once used to identify the factors, may respond to all shocks on impact inasmuch as they are contemporaneously related to the factors through the unrestricted part of the loading matrix (i.e., the $\lambda_{0,2}$ matrix in equation (15)). Thus, the recursive structure is only applied to identify the shocks. Together, equations (15) and (16) make the structural BDFM uniquely identified.

\footnotetext{
${ }^{15}$ However, as shown in Kilian (2009), and a range of subsequent papers, such supply shocks explain a trivial fraction of the total variance in the price of oil, and do not account for a large fraction of the variation in real activity either.
} 


\subsection{Estimation}

Let $\tilde{y}_{T}=\left[y_{1}, \cdots, y_{T}\right]^{\prime}$ and $\tilde{f}_{T}=\left[f_{1}, \cdots, f_{T}\right]^{\prime}$, and define $H=\left[\lambda_{0}, \cdots, \lambda_{s}\right], \beta=\left[\phi_{1}, \cdots, \phi_{h}\right]$, $\mathrm{Q}, \mathrm{R}$, and $p_{i}=\left[\rho_{1, i}, \cdots, \rho_{l, i}\right]$ for $i=1, \cdots, N$, as the model's hyper-parameters.

Inference in our model can be performed using both classical and Bayesian techniques. In the classical setting, two approaches are available, two-step estimation and maximum likelihood estimation (ML). In the former, $\tilde{f}_{T}, H$ and $R$ are first typically estimated using the method of principal components analysis (PCA). Following this, the dynamic components of the system, $A$ and $Q$, are estimated conditional on $\tilde{f}_{T}, H$ and $R$. Thus, the state variables are treated as observable variables. If estimation is performed using ML, the observation and state equations are estimated jointly. However, ML still involves some type of conditioning. That is, we first obtain ML estimates of the model's unknown hyper-parameters. Then, to estimate the state, we treat the ML estimates as if they were the true values for the model's non-random hyper-parameters. In a Bayesian setting, both the model's hyper-parameters and the state variables are treated as random variables.

We have estimated the DFM using both the two-step procedure and Bayesian estimation. The results reported in Section 4 are not qualitatively affected by the choice of estimation method. However, we prefer the Bayesian approach primarily for the following reasons. 1) In contrast to the classical approach, inferences regarding the state are based on the joint distribution of the state and the hyper-parameters, not a conditional distribution. 2) ML estimation would be computationally intractable given the number of states and hyper-parameters. 3) Our data are based on logarithmic year-on-year differences. This spurs autocorrelation in the idiosyncratic errors. In a Bayesian setting, the model can readily be extended to accommodate these features of the error terms. In a classical two-step estimation framework, this is not the case. Furthermore, in the two-step estimation procedure, it is not straightforward to include lags of the dynamic factors in observation equation.

Thus, our preferred model is a Bayesian Dynamic Factor Model (BDFM). We set, $s=2, h=8$, and $l=1$. That is, we include 2 lags for the dynamic factors in the observation equation (see equation 10), 8 lags in the transition equation (see equation 11), and let the idiosyncratic errors follow $\mathrm{AR}(1)$ processes (see equation 13). ${ }^{16}$ In Appendix C.1 we explain the choice of this particular specification and analyse its robustness.

Bayesian estimation of the state space model is based on Gibbs simulation, see Appendix D for details on simulation and our choice of prior specifications. We simulate the model using a total of 50,000 iterations. A burn-in period of 40,000 draws is employed, and only every fifth iteration is stored and used for inference. ${ }^{17}$

\subsection{Data}

To accommodate resource movement and spending effects, the observable $y_{t}$ vector includes a broad range of sectoral employment and production series. The full list, for

\footnotetext{
${ }_{16}$ Note that we let $s=0$ and $l=0$ when estimating the DFM using the two-step estimation procedure.

${ }^{17}$ Standard MCMC convergence tests confirm that the Gibbs sampler converges to the posterior distribution. Convergence statistics are available on request.
} 
each country, is reported in Appendix A. Although we can construct labour productivity estimates directly from our model estimates (since we include both production and employment at the sectoral level), we also include productivity as an observable variable within the $y_{t}$ vector. Naturally, we also include the real exchange rate, which is a core variable in the Dutch disease literature. To account for wealth effects, and to facilitate the interpretation and identification of the structural shocks, we also include wage and investment series, the terms of trade, stock prices, consumer and producer prices, and the short term interest rate.

In Norway, the real commodity price is the real price of oil, which is constructed on the basis of Brent Crude oil prices (U.S. dollars). In Australia we use the Reserve Bank of Australia's (RBA) Index of Commodity Prices (U.S. dollars). Both commodity prices are deflated using the U.S. CPI. For Norway, we measure global or world activity as the simple mean of four-quarter logarithmic changes in real GDP in Denmark, Germany, the Netherlands, Sweden, the UK, Japan, China, and the U.S. This set of countries includes Norway's most important trading partners and the largest economies in the world. For the same reason we use for Australia: New Zealand, Singapore, the UK, Korea, India, Japan, China, and the U.S.

In sum, this gives a panel of roughly 50 international and domestic data series (for each country), covering a sample period from 1991:Q1 to 2012:Q4 (Australia), and 1996:Q1 to 2012:Q4 (Norway). ${ }^{18}$ To capture the economic fluctuations of interest, we transform all variables to four-quarter logarithmic changes; $\left.\log \left(y_{i, t}\right)-\log \left(y_{i, t-4}\right)\right)$. Lastly, all variables are demeaned before estimation.

\section{Results}

Below we first present the identified factors before describing the resource sectors in the two countries in more detail. We then investigate the main propagation mechanisms following an unexpected resource gift in terms of either a resource boom or commodity price shock. Finally, we examine sectoral reallocation following these shocks.

\subsection{Global and domestic factors and impulse responses}

The global activity factor and commodity prices are observable variables in our model and are graphed in the first row in Figure 3. We note how the real oil price is more volatile than the relevant real commodity price index for Australia. The two indexes of global activity are very similar, except the Asian crisis is more visible in the global activity index used in the model for Australia.

The second row in Figure 3 reports the estimated resource and domestic activity factors for Norway (left) and Australia (right). The resource activity factor for Australia captures developments specifically linked to the mining industry, while in Norway, the factor is associated with extraction of oil and gas. As expected, the volatilities of the resource activity factors are rather large, and for Norway larger than the volatility of the

${ }_{18}^{18}$ The sample periods reflect the longest possible time period for which a full panel of observables is available for the two countries respectively. 
Figure 3. Estimated factors

Model for Norway

Global activity

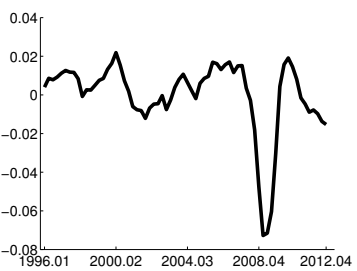

Resource activity

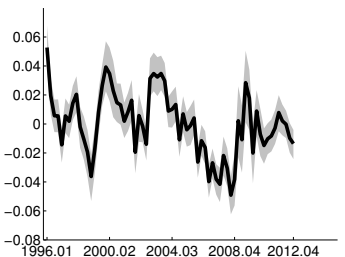

Real oil price

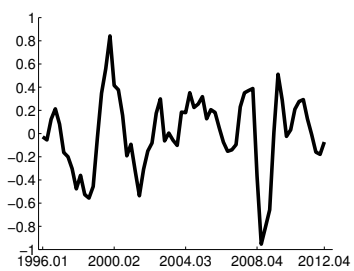

Domestic activity

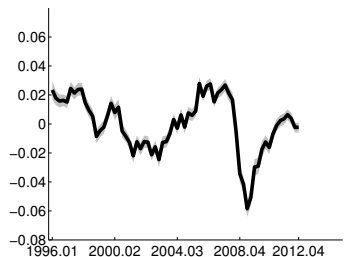

Model for Australia

Global activity

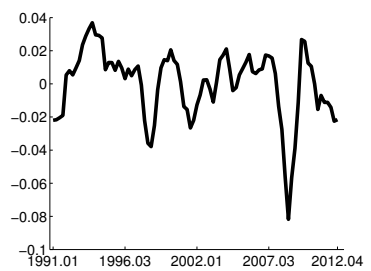

Resource activity

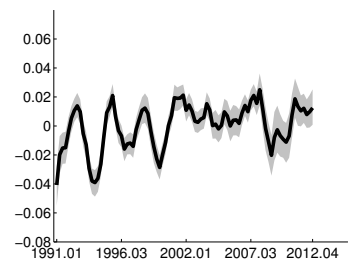

Real com. price

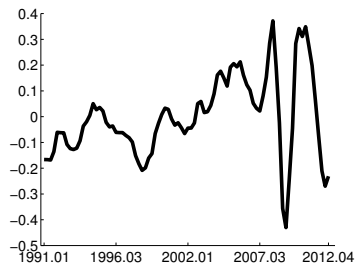

Domestic activity

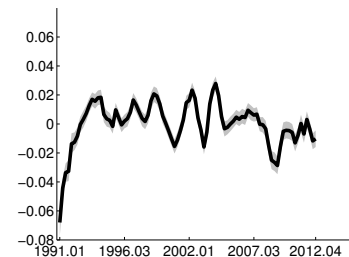

Note: The figures display the estimated latent factors. The black solid lines are median estimates. The grey shaded areas are 68 percent probability bands

domestic activity factor. There are also some difference in persistence between the two countries, with a long lasting boom in the oil and gas sector in Norway in the early and mid 1990s, and also in the period between 2000 and 2004, but followed by a long period of downsizing in the mid 2000s. For Australia, the many boom and bust periods in the mining industry in the 1990s are clearly visible, but then there is a long period of stable and high growth from 2002/2003. Note also the recession in the domestic economy in Australia at the beginning of the 1990s, which was the worst recession for decades.

In the interest of brevity we report the impulse responses associated with the international part of the model as well as the domestic activity shock in Figures 9 and 11 in Appendix B. As seen there, the international shocks in the model are well identified. That is, the global activity shock increases both the activity level and real commodity prices, while unexpected commodity price shocks generate a temporary inverse relationship between the commodity prices and global activity. While the temporary inverse relationship between commodity prices and the global economy is in line with Hamilton (2009), the results are also consistent with recent studies emphasizing the role of global demand as a driver of oil prices, see, e.g., Kilian (2009), Lippi and Nobili (2012) and Aastveit et al. (2014) among many others.

A domestic activity shock raises GDP, employment, wages, and prices in the domestic economy. The effect on investment is also positive, but the variation explained by the domestic shock is modest, at least in Norway (see Tables 2 and 3). The effect on the real exchange rate or the terms of trade is negligible in both countries. Hence, this shock may capture the effect of a domestic demand. Interestingly, in Norway, employment and wages are explained mainly by the domestic shock whereas GDP and Investment are explained mainly by the global activity shock (plus the resource sector shock). This also 
holds for Australia, although domestic shocks explain more of the investment and GDP dynamics than they do in Norway (as Norway is more open and resource dependent). We believe the dichotomy relates to the usual transmission mechanisms, whereas wages and employment respond quickly to domestic impulses (public and private demand), while investment requires more foreign capital inflow, and hence is linked more closely with global dynamics.

\subsection{What describes a resource boom?}

Norway and Australia are both net resource exporters. The resource industry in the two countries is, however, very different. In Norway, resource wealth is extracted almost exclusively from oil and gas extraction offshore, hundreds of meters below the sea surface. In recent decades, the exploration of natural resources has also moved further north and to deeper depths, requiring even more sophisticated technology to accommodate the harsher conditions and subsea exploration. Australia extracts and exports a large range of minerals (including some oil and gas), though the iron ore industry was the principal factor fuelling the recent boom. The main technical difficulty with extracting iron ore is not necessarily finding it, the grade or size of the deposits, but rather the position of the iron ore relative to the market and the energy and transportation costs required to get it to the market.

Another important difference between the two countries is the degree of openness. In terms of the openness indicator computed by World Penn Tables, Norway is almost twice as open as Australia. ${ }^{19}$ Common for both the oil and gas industry in Norway and the mining industry in Australia is the fact that both industries are highly capital intensive.

Our results are consistent with these facts. The resource activity shock, together with the commodity price shock, explain as much as 70-90 percent of the variation in production, employment, wages, and investment in the resource sectors in Norway and Australia, see Table 1. In both countries, the resource boom is particularly associated with increased value added and employment dynamics. This is consistent with the interpretation of the shock as an (unpredicted) technical improvement in the booming sector, represented by a favourable shift in the production function, or a windfall discovery of new resources.

Interestingly, the bulk of the variation in petroleum and mining investment is explained by the commodity price shocks (that drive up commodity prices), see Table 1 . In Australia, mining investments increase for 1-2 years after this shock, while for petroleum investments in Norway, the increase is delayed for a year, but picks up and peaks after three years (these responses are not shown, but can be obtained on request). The fact that petroleum investments increase with a lag relative to mining investments in Australia, is consistent with a shorter lead time from discovery to exploration in the mining industry than in the offshore petroleum industry.

Lastly, global demand shocks (that drive up commodity prices) also affect activity and employment in the mining and petroleum sectors, and in particular investment. Between 20-30 percent of the variation in petroleum and mining investment refers back to global

${ }^{19}$ According to Pen World Tables, openness in Norway and Australia is respectively 73 percent and 40 percent on average the last decade (current or constant prices). 
Table 1. Variance decompositions: Resource sector

\begin{tabular}{|c|c|c|c|c|c|}
\hline & \multirow[b]{2}{*}{ Variable } & \multicolumn{4}{|l|}{ Shock } \\
\hline & & $\begin{array}{l}\text { Resource } \\
\text { activity }\end{array}$ & $\begin{array}{c}\text { Commodity } \\
\text { price }\end{array}$ & $\begin{array}{c}\text { Global } \\
\text { activity }\end{array}$ & $\begin{array}{c}\text { Domestic } \\
\text { activity }\end{array}$ \\
\hline & \& Horizon & 4,8 & 4,8 & 4,8 & 4,8 \\
\hline \multirow{4}{*}{ 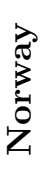 } & GDP - oil and gas & $0.86,0.65$ & $0.07,0.09$ & $0.02,0.15$ & $0.05,0.10$ \\
\hline & Employment - oil and gas & $0.59,0.58$ & $0.33,0.34$ & $0.07,0.05$ & $0.01,0.03$ \\
\hline & Wages - oil and gas & $0.47,0.34$ & $0.33,0.25$ & $0.15,0.23$ & $0.05,0.18$ \\
\hline & Investment - oil and gas & $0.02,0.06$ & $0.72,0.43$ & $0.17,0.29$ & $0.09,0.21$ \\
\hline \multirow{4}{*}{ 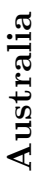 } & GDP - mining & $0.91,0.86$ & $0.05,0.11$ & $0.03,0.02$ & $0.01,0.01$ \\
\hline & Employment - mining & $0.79,0.58$ & $0.06,0.15$ & $0.09,0.24$ & $0.06,0.03$ \\
\hline & Wages - mining & $0.26,0.24$ & $0.13,0.15$ & $0.06,0.05$ & $0.55,0.55$ \\
\hline & Investment - mining & $0.27,0.21$ & $0.66,0.59$ & $0.06,0.20$ & $0.02,0.01$ \\
\hline
\end{tabular}

Note: Each row-column intersection reports median variance decompositions for horizons 4 (left) and 8 (right)

demand and its effect via higher commodity prices. As the most open of the two countries, Norway is also the most affected by global demand.

\subsection{Resource booms and domestic impulse responses}

Now we focus on our core question: How do the domestic variables respond to the resource activity shock described above? Figure 4 reports the responses for the key variables in the domestic economy: (non-resource) GDP, productivity, (non-resource) employment and the real exchange rate, after a resource boom.

In line with the predictions from the theory model, we confirm that there are large and positive spillovers from the exploration of natural resources to the non-resource industries in both Australia and Norway. In particular, in the wake of the resource boom, productivity increases for a prolonged period of time in both countries (although the effect is more uncertain for Australia). This suggests that productivity spillovers are important for the resource boom shock. As productivity measures the efficiency of production, this also explains why output in the domestic economy increases substantially following this shock. This is interesting, as it highlights the empirical relevance of alternative theoretical Dutch disease models, like the one put forward above. Variance decompositions in Table 2 confirm that the expansion in Norway is substantial; After 1-2 years, 25-30 percent of the variation in non-resource GDP is explained by the resource boom, while the comparable numbers are 43-50 percent for productivity. In Australia the expansion is more modest; 10-15 percent of value added in non-mining is explained by the resource boom, while 5-6 percent of productivity is explained by the same shock. The effect on employment, however, is initially weak, but increases slightly in both countries, and is highly significant after about 1-2 years in Norway. After two years, the resource boom shock explains about 10 percent of the variation in employment in Norway and less than 
Figure 4. Norway and Australia. Resource gifts and domestic responses

GDP

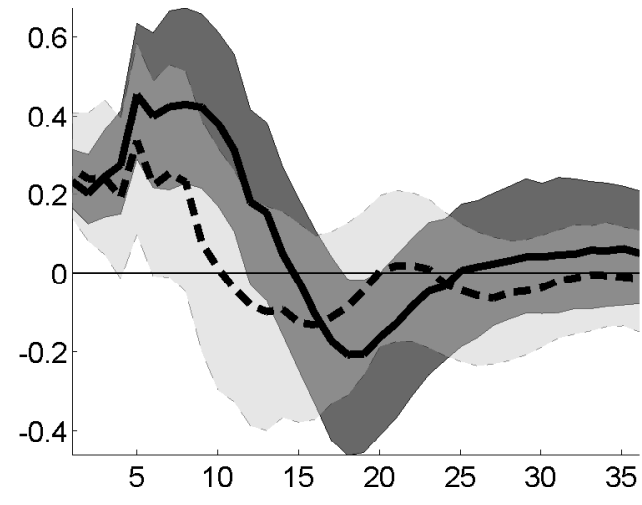

Employment

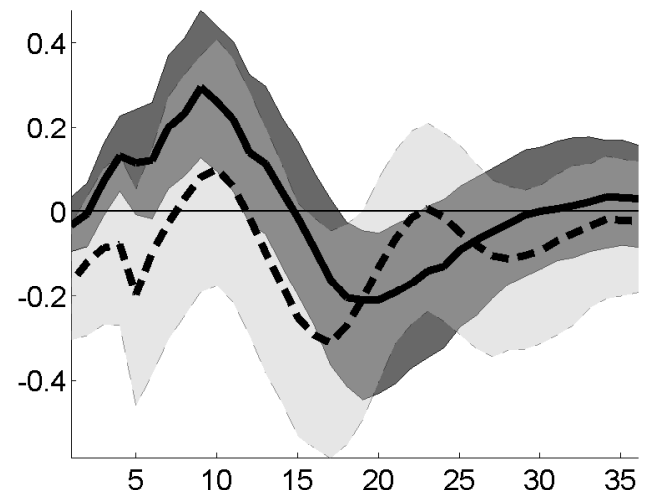

Productivity

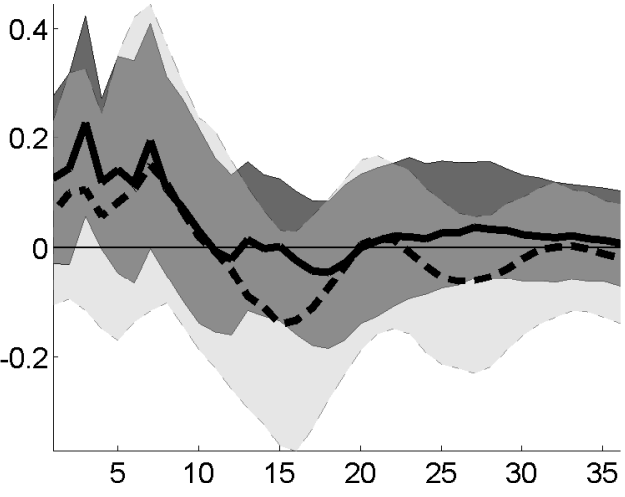

Real exchange rate

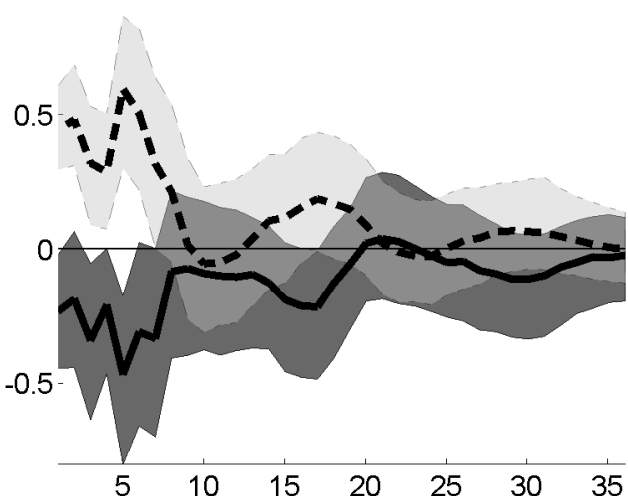

Note: In each plot, Norway (Australia) is the solid (dotted) line with the associated dark (light) grey probability bands. The responses are displayed in levels of the variables. The resource boom shock is normalized to increase the resource activity factor by 1 percent. The shaded areas (dark and light grey) represent 68 percent probability bands, while the lines (solid and dotted) are median estimates

5 percent in Australia, see Table 2.

The difference in the importance of the spillovers in Australia and Norway could reflect the fact that the resource sector represents a larger share of the economy in Norway than in Australia (20 versus 10 percent). Yet, it cannot explain the very substantial productivity spillovers from the resource sector to domestic variables in Norway. The continuous development of new drilling and production technology discussed in Section 4.2 above could be an important factor in explaining the success and the boost in productivity in Norway. We return to this issue below when we discuss sectoral responses.

Lastly, the responses in the real exchange rate differ across the two countries. In Norway, the response is small and mostly insignificant, if anything, showing evidence of real depreciation. This also helps explain why energy booms can have such stimulative effects on the mainland economy. For Australia, there is first an appreciation, but then the exchange rate depreciates slightly. This is in line with the predictions given by the theory model above, when there are productivity spillovers. 
Table 2. Norway and Australia. Resource gifts and domestic variance decompositions

\begin{tabular}{|c|c|c|c|c|c|}
\hline & \multirow[b]{2}{*}{ Variable } & \multicolumn{4}{|l|}{ Shock } \\
\hline & & $\begin{array}{l}\text { Resource } \\
\text { activity }\end{array}$ & $\begin{array}{l}\text { Commodity } \\
\text { price }\end{array}$ & $\begin{array}{l}\text { Global } \\
\text { activity }\end{array}$ & $\begin{array}{c}\text { Domestic } \\
\text { activity }\end{array}$ \\
\hline & \& Horizon & 4,8 & 4,8 & 4,8 & 4,8 \\
\hline \multirow{4}{*}{ 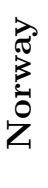 } & GDP & $0.23,0.30$ & $0.05,0.02$ & $0.56,0.54$ & $0.16,0.14$ \\
\hline & Productivity & $0.43,0.50$ & $0.18,0.14$ & $0.25,0.23$ & $0.13,0.13$ \\
\hline & Employment & $0.06,0.09$ & $0.09,0.07$ & $0.31,0.44$ & $0.53,0.39$ \\
\hline & Real exchange rate & $0.08,0.16$ & $0.69,0.63$ & $0.24,0.21$ & $0.00,0.00$ \\
\hline \multirow{4}{*}{ 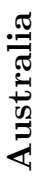 } & GDP & $0.11,0.12$ & $0.02,0.11$ & $0.27,0.22$ & $0.59,0.56$ \\
\hline & Productivity & $0.05,0.06$ & $0.46,0.56$ & $0.06,0.05$ & $0.43,0.33$ \\
\hline & Employment & $0.04,0.03$ & $0.16,0.42$ & $0.15,0.07$ & $0.66,0.48$ \\
\hline & Real exchange rate & $0.40,0.42$ & $0.06,0.11$ & $0.49,0.44$ & $0.06,0.03$ \\
\hline
\end{tabular}

Note: See Table 1

\subsection{Commodity prices and domestic responses}

There are two structural shocks that increase commodity prices, a global activity shock and a commodity (specific) price shock. When the increase in commodity prices is due to a global activity shock, the effect on the domestic economy is primarily positive, as GDP and employment rise for a prolonged period of time in both countries, see Figure 10, Appendix B. This is in line with what others have also found, see e.g., Aastveit et al. (2014). What is interesting to note here, is the large positive effect on the Norwegian economy relative to Australia. As documented in Table 2, global activity shocks explain roughly 55 and 25 percent of the variation in overall activity in Norway and Australia, respectively. This is perfectly in match with the fact that Norway is close to twice as open as Australia by conventional estimates. It is also in line with the fact that since global demand boosts commodity prices, this may have benefited the more resource rich economy, Norway, to a larger extent. Norway also experienced a temporary appreciation of the real exchange rate following this shock. The finding that foreign factors are important, but to varying degrees, for small open economies is also well documented in, e.g., Aastveit et al. (2015) and Furlanetto et al. (2013).

We now turn to the commodity (specific) price shock, which is the shock typically analysed in the empirical Dutch disease literature. An increase in commodity prices due to this shock, will be contemporaneously unrelated to global activity. Figure 5 reports the key responses. ${ }^{20}$ While productivity and production in both Australia and Norway increase for a prolonged period of time following a resource boom shock, the effect of a commodity price shock is less favourable. In particular, a commodity price shock has

${ }^{20} \overline{\text { Following the standard convention in the }}$ oil market literature we have normalized the commodity price shock to an initial 10 percent increase in the real price of oil (Norway). Since the standard deviation of the commodity price index is half the size of the real price of oil, we have normalized the shock to the commodity price index to an initial 5 percent increase. 
Figure 5. Norway and Australia. Commodity price shocks and domestic responses
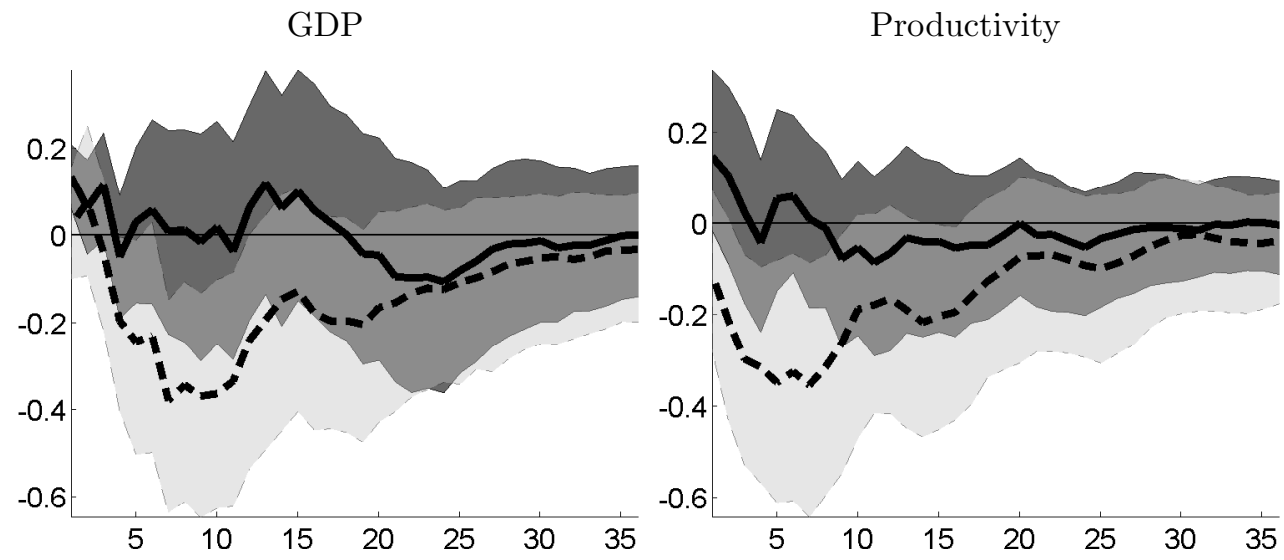

Employment

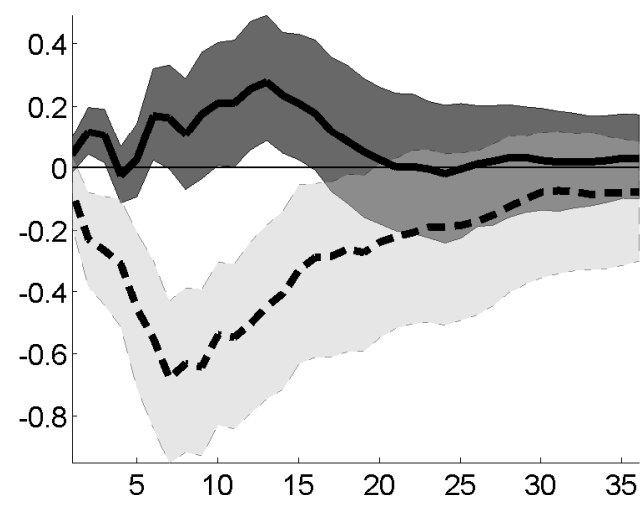

Real exchange rate

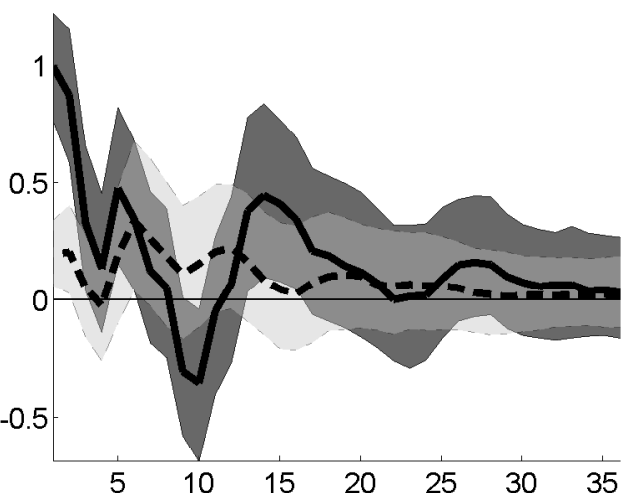

Note: In each plot, Norway (Australia) is the solid (dotted) line with the associated dark (light) grey probability bands. The commodity price shock is normalized to increase the real price of oil (commodity price index) with 10 (5) percent. See also the note to Figure 4

either no effect on productivity (Norway), or affects productivity negatively (Australia).

Further, in Norway, the commodity price increase is strongly associated with a real exchange rate appreciation. Over 60 percent of the variation in the real exchange rate is explained by this shock. The strong appreciation increases cost and reduces competitiveness, and will potentially hurt the sectors exposed to foreign competition. As a consequence, output and employment only increase marginally following this shock. In Australia the commodity shock explains much less of the variation in the exchange rate. Still, the negative productivity effects and modest appreciation of the exchange rate are also coupled with a large drop in employment and production. Our result of an appreciating exchange rate is well in line with the other empirical studies of commodity currencies, see, e.g., Chen and Rogoff (2003).

The results reported above show that is important to distinguish between windfall gains due to volume and price changes when analysing the Dutch disease hypothesis. Although the production and productivity responses following a resource boom shock show large similarities across the two countries, in line with the theory model, the variance decompositions for both shocks, and the results regarding the commodity price shock in 
particular, suggest that the transmission channels might differ. We examine and discuss these, and to what extent the two economies show Dutch disease symptoms and two-speed patterns, in greater detail below.

\subsection{Additional transmission channels}

Central to our theory model are productivity spillovers, discussed above. Central to more classical Dutch disease theories are resource movement and spending effects, including substantial income and wealth effects. In Figure 6 and Table 3 we examine how domestic (non-resource) investment, wages, producer prices (PPI), consumer prices (CPI), stock prices, and the terms of trade are affected by the resource activity shocks and commodity price shocks, respectively.

First, in Norway, a resource activity boom is accompanied by a substantial investment boom in the domestic economy as well. With a lag, wages also increases, while the responses in PPI, CPI, stock prices and the terms of trade are minor, and hardly significant. From Table 3 we see that the resource boom does not explain a large share of the variation in these variables, but does explain a substantial part of the variation in domestic investment. Thus, the resource boom shock in Norway does not affect costs, but does change the distribution of wealth due to productivity spillovers (learning by doing) and subsequent movement of resources, higher income and increased spending in the overall economy. In Australia, the resource boom shock is of less importance for the domestic economy (as shown in Table 2), and investment in the domestic economy actually falls for a prolonged period after this shock. This suggests a crowding out effect from mining in Australia. As in Norway, the resource boom shock does not explain much of the variation in PPI, stock prices, the terms of trade, and wages, albeit somewhat more of the variation in CPI. Overall, these results confirm the interpretation and identification of the resource boom shock as linked to either an (unpredicted) technical improvement in the booming sector, represented by a favourable shift in the production function, or as a windfall discovery of new resources.

Second, a commodity price shock has some positive effects on the domestic economy. Investment, in particular, increases temporarily in both countries, most likely as petroleum and mining investment also rise and because the exchange rate appreciates. As discussed in Spatafora and Warner (1999), a commodity price shock can lead to a reduction in the relative price of investment goods, which are predominantly tradable, implying a positive correlation between commodity prices and investment. Wages also gradually increase, suggesting there are spending effects owing to the windfall gains associated with increased commodity prices. The responses in investments, wages, PPI, and CPI are remarkably similar across the two countries. The rise in consumer and producer costs erodes the real effect of spending, and may explain why the commodity price shock has less stimulating (or negative) effects on the economy. As expected, the terms of trade also improves in both countries, but the response in Australia is substantially more pronounced. The stock market responses are in line with the fact that the shock has a positive effect on overall activity level in the Norwegian economy, but a negative effect on the Australian economy (see Figure 4). While the fall in the stock price index for Australia might seem 
Figure 6. Norway and Australia: Wealth, cost and investment responses
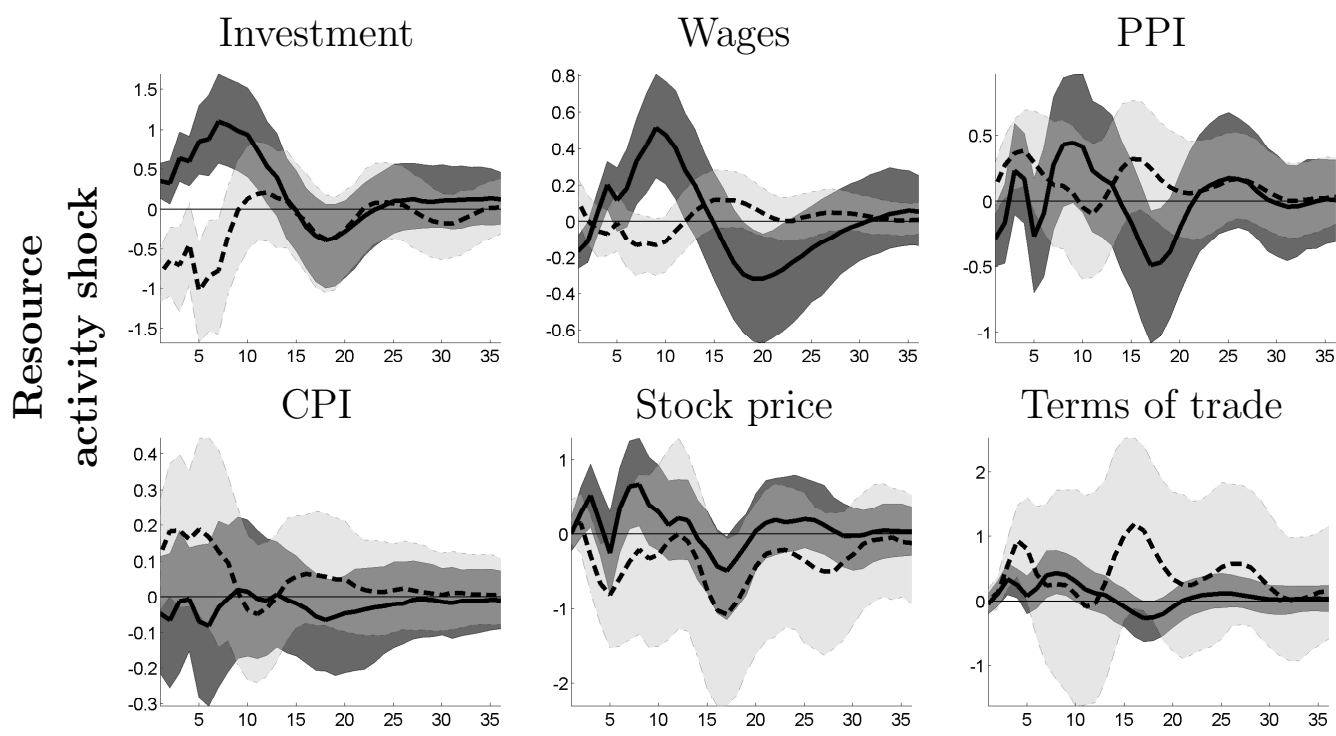

Stock price

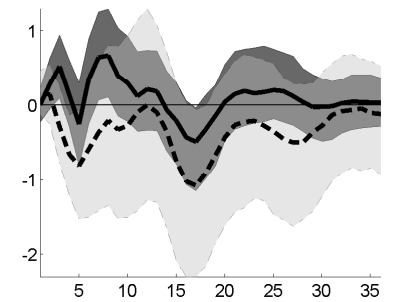

Terms of trade

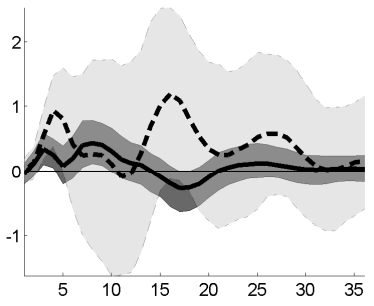

Investment
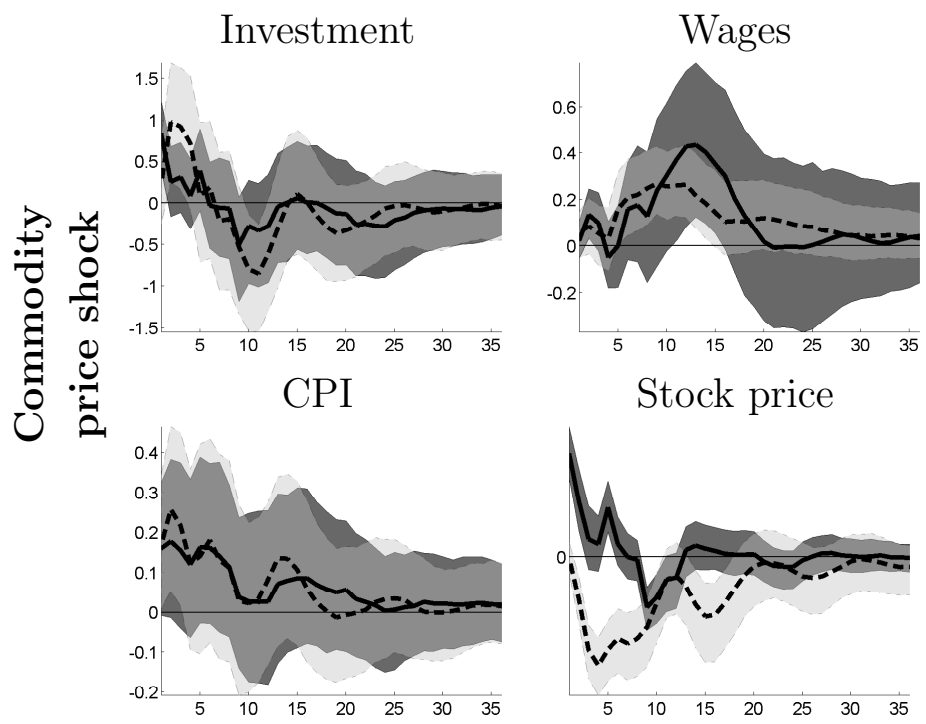

PPI

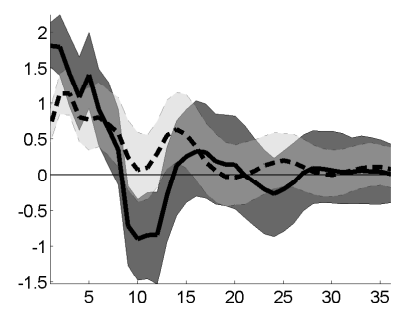

Terms of trade
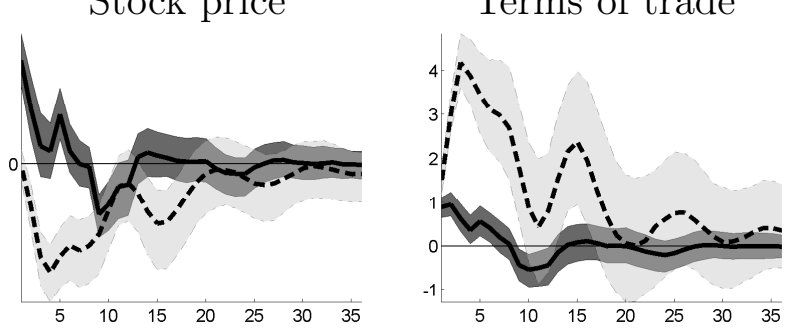

Note: In each plot, Norway (Australia) is the solid (dotted) line with the associated dark (light) grey probability bands. See also the note to Figures 4 and 5

surprising, it is also found in, e.g., Ratti and Hasan (2013). Moreover, asset prices are the present discounted values of the future net earnings of the firms in the economy. Unexpected commodity price shocks that increase (decrease) the production possibilities for the whole economy should be positively (negatively) related to stock returns.

To sum up, both Norway and Australia have benefited from having highly profitable commodity sectors. In Norway, windfall gains due to energy booms have had positive spillover effects on the mainland economy, but the shock does not affect costs. In Australia, the resource boom in the mining industry has had similar, although more modest, spillovers. In terms of the theory model developed in Section 2, this suggests a positive $\delta_{R}$ for both countries, but higher in Norway than Australia. On the other hand, the large 
Table 3. Norway and Australia: Wealth, cost and investment variance decompositions

\begin{tabular}{|c|c|c|c|c|c|}
\hline & \multirow[b]{2}{*}{ Variable } & \multicolumn{4}{|l|}{ Shock } \\
\hline & & $\begin{array}{c}\text { Resource } \\
\text { activity }\end{array}$ & $\begin{array}{c}\text { Commodity } \\
\text { price }\end{array}$ & $\begin{array}{l}\text { Global } \\
\text { activity }\end{array}$ & $\begin{array}{c}\text { Domestic } \\
\text { activity }\end{array}$ \\
\hline & \& Horizon & 4,8 & 4,8 & 4,8 & 4,8 \\
\hline \multirow{6}{*}{$\begin{array}{l}\overrightarrow{2} \\
\hat{3} \\
0 \\
\text { Z }\end{array}$} & PPI & $0.01,0.02$ & $0.67,0.59$ & $0.31,0.38$ & $0.01,0.01$ \\
\hline & CPI & $0.04,0.05$ & $0.70,0.61$ & $0.14,0.16$ & $0.12,0.17$ \\
\hline & Stock price & $0.01,0.04$ & $0.69,0.63$ & $0.29,0.33$ & $0.01,0.01$ \\
\hline & Terms of trade & $0.04,0.07$ & $0.53,0.41$ & $0.42,0.50$ & $0.02,0.02$ \\
\hline & Investment non-resource & $0.16,0.28$ & $0.17,0.07$ & $0.60,0.60$ & $0.06,0.05$ \\
\hline & Wages non-resource & $0.11,0.11$ & $0.05,0.03$ & $0.40,0.54$ & $0.44,0.32$ \\
\hline \multirow{6}{*}{ 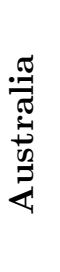 } & PPI & $0.06,0.04$ & $0.60,0.43$ & $0.33,0.52$ & $0.01,0.02$ \\
\hline & CPI & $0.25,0.22$ & $0.38,0.27$ & $0.27,0.42$ & $0.09,0.09$ \\
\hline & Stock price & $0.02,0.02$ & $0.87,0.71$ & $0.10,0.26$ & $0.01,0.01$ \\
\hline & Terms of trade & $0.02,0.01$ & $0.72,0.54$ & $0.26,0.44$ & $0.00,0.01$ \\
\hline & Investment non-resource & $0.19,0.25$ & $0.26,0.15$ & $0.36,0.42$ & $0.19,0.18$ \\
\hline & Wages Non-resource & $0.07,0.08$ & $0.05,0.26$ & $0.10,0.08$ & $0.78,0.58$ \\
\hline
\end{tabular}

Note: See Table 1

share of the variance explained by the resource boom and the shocks driving commodity prices in Norway also suggests that Norway, as an economy, is more dependent on petroleum resources than Australia on mining.

The commodity price shock affects costs and wages across the two countries in the same manner, but has a clear negative effect on production and employment in Australia. This is evidence of more classical Dutch disease-like symptoms. We examine this issue in greater detail below, focusing in particular on sectoral responses in the private sector and the role of the public sector as shock absorber in the resource rich economies.

\subsection{Dutch disease or two-speed boom?}

The standard theory of Dutch disease predicts that some sectors of the economy (tradables) will contract, and others expand (non-tradables) as a result of an unexpected resource gift. The theory model outlined in Section 2 allows, but does not constrain, all sectors to move in the same direction. The results presented in Figures 7 and 8 cast light on the empirical relevance of these two competing theories. In the figures we display the responses in value added and employment across a large panel of sectors to an energy boom (top panels) and a commodity price shock (bottom panels) in Norway and Australia, respectively. The figures display the quarterly average of each sector's response (in levels) to the different shocks, while white bars indicate that the shock explains less than 10 percent of the variation in that sector. Table 5 in Appendix B reports the exact numbers.

Overall, the results presented in the figures show that the resource boom shock and 
Figure 7. Norway: Sectoral responses
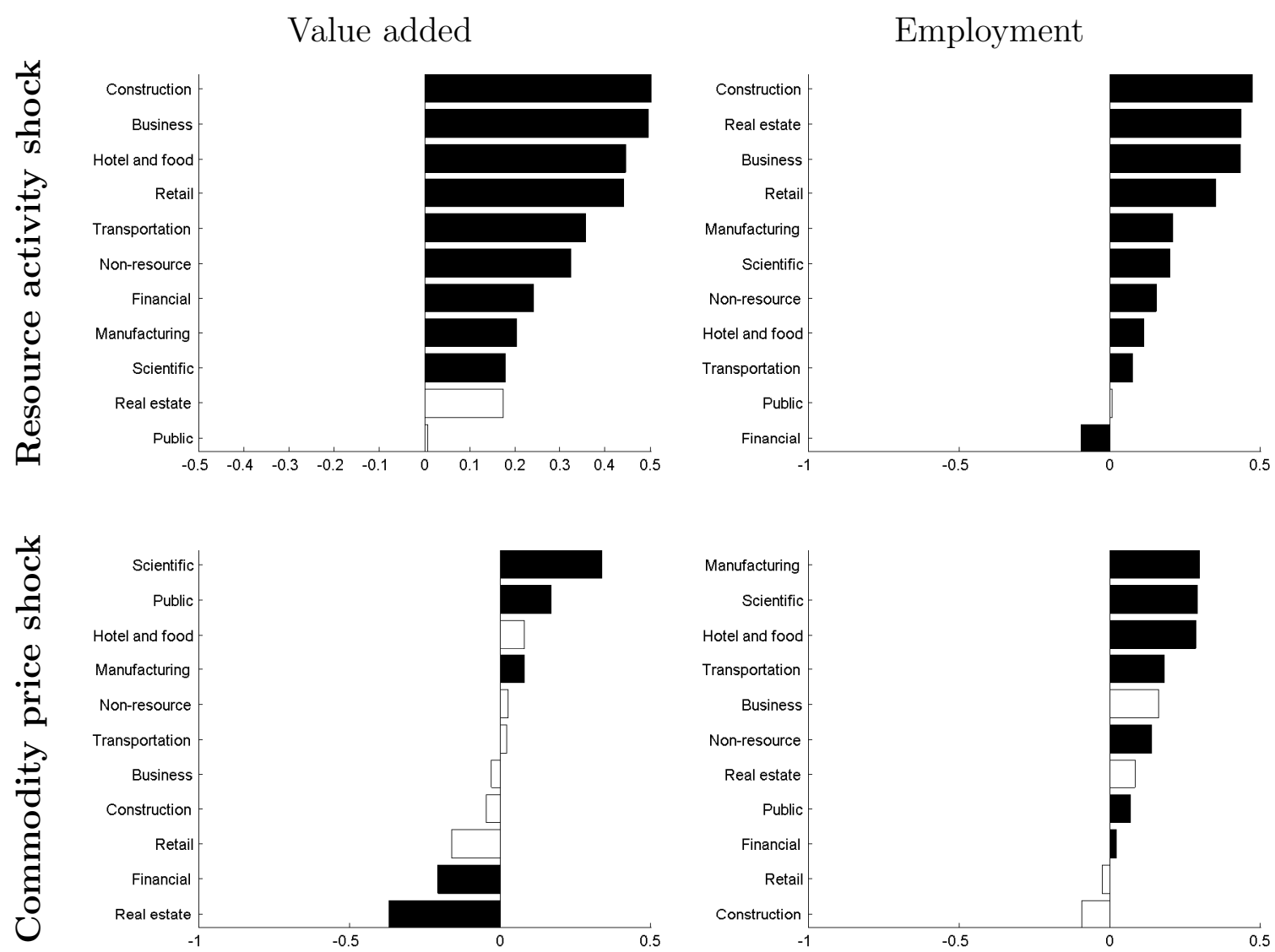

Note: Each plot displays the quarterly average of each sector i's response (in levels) to the different shocks. The averages are computed over horizons 1 to 12. The resource activity shock is normalizes to increase the resource activity factor by 1 percent, while the commodity price shock is normalized to increase the real price of oil by 10 percent. White bars indicate that the shock explains less than 10 percent of the variation in the sector

the commodity price shock have contributed to turn Australia and Norway into two-speed economies, with some industries growing at a fast speed and others growing more slowly, or in fact declining. ${ }^{21}$ However, while most sectors are positively affected by the resource boom shock in both Norway and Australia, the commodity price shock works almost in opposite directions across the two countries.

Starting with Norway, Figure 7 emphasizes how energy booms stimulate value added in all industries in the private sector, although to varying degrees. The construction and business sectors are among the most positively affected. Between 30 and 40 percent of the variance in these sectors is explained by energy booms, see Table 5 in Appendix B. These are industries with moderate direct input into the oil sector, but the indirect effects are large. Value added in manufacturing is also positively affected, but less so than in the non-tradable sectors. Nonetheless, there is no evidence of Dutch disease wherein the

${ }^{21}$ The two-speed pattern observed in the data, see, e.g. Figure 1, is a function of all potential shocks, including idiosyncratic disturbances. Our focus is on the two resource gift shocks, which are at the core of (theoretical) classical Dutch disease models, and in the model presented in Section 2. 
Figure 8. Australia: Sectoral responses
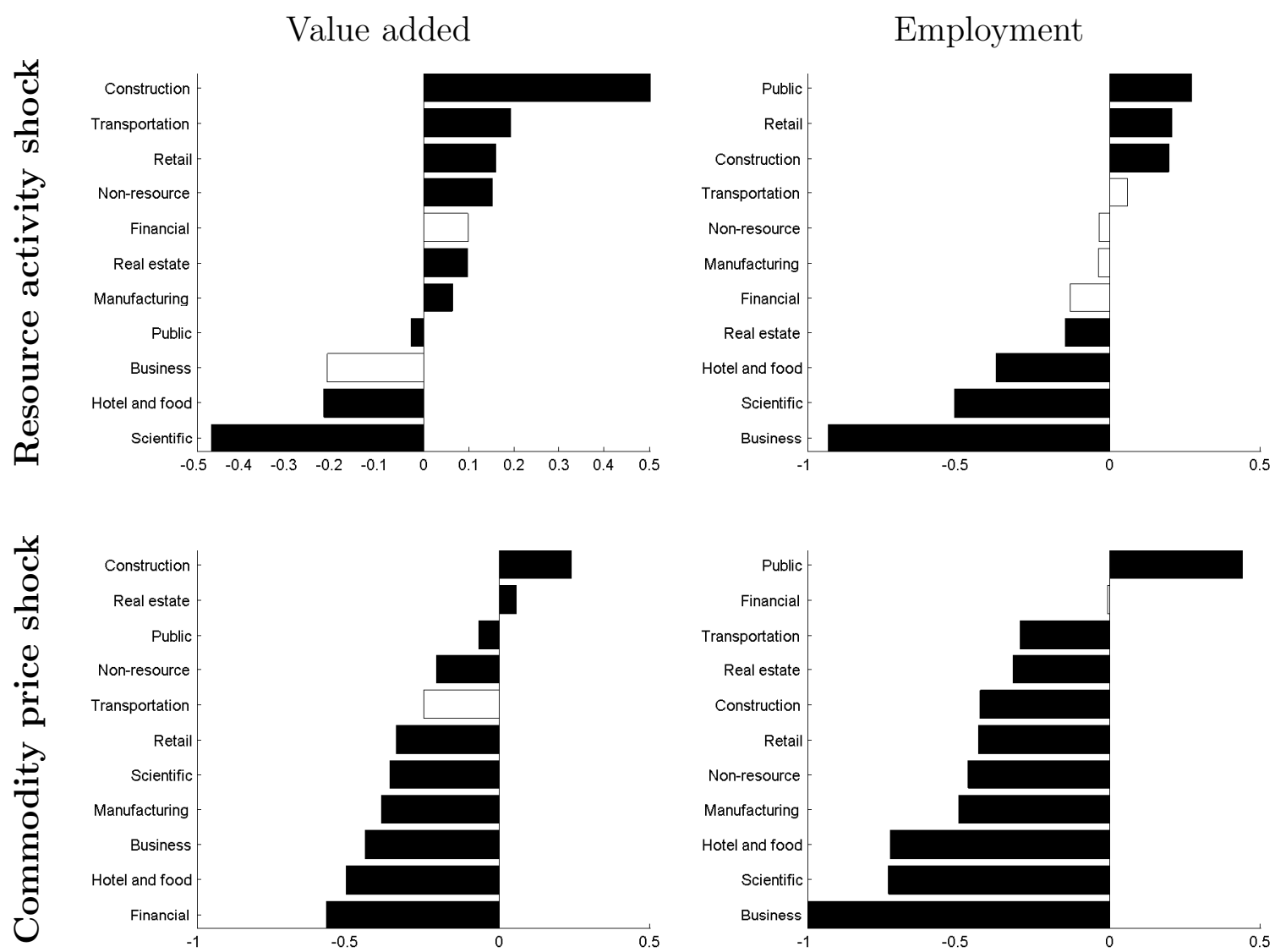

Note: See Figure 7. The commodity price shock is normalized to increase the commodity price index by 5 percent

sector eventually contracts. ${ }^{22}$

Turning to the labour market, we can confirm that the resource boom shock has indeed contributed to making Norway a two-speed economy, with employment in nontraded sectors such as construction, the business service sector and real estate growing at a much faster pace than traded sectors such as manufacturing. However, and as above, there is no evidence of Dutch disease: manufacturing does not contract. Interestingly, the effect on the public sector (for both value added and employment) is much smaller than for most of the other sectors, suggesting only a minor government spending effect following this shock.

As seen in Table 5, and indicated by the white bars in Figures 7, the commodity price shock generally explains a substantially smaller share of the variance of the value added at the industry level in Norway than the resource activity shock does. Sectors such as scientific services and manufacturing are among the most positively affected. This is

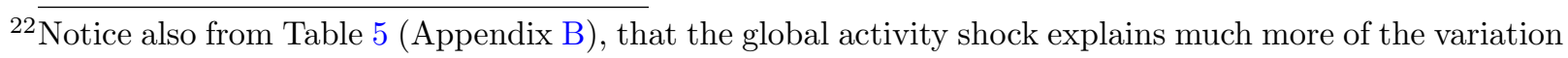
in manufacturing than in the public sector. Since the manufacturing and the public sector are typically considered as a tradable and non-tradable sectors respectively, this provides evidence that our model indeed indirectly captures the tradable versus non-tradable distinction, see Section 3. 
interesting, as these sectors are also technology intensive and enjoy spillovers from the significant boost in petroleum investments following from the commodity price shock. As offshore oil often demands complicated technical solutions, the shock generated positive knowledge externalities that benefitted employment in these sectors in particular. Thus, the theory of Dutch disease is turned on its head following this shock. Furthermore, compared to the responses reported for the resource activity shock, the public sector is now also positively affected, suggesting the presence of a substantial spending effect. In light of the higher commodity prices of the past decade, this can have worked to boost demand in the Norwegian economy relative to other oil-importing countries. However, as emphasized in the previous section, the increased spending could also suggest why cost competitiveness has declined and may be a concern in the long run. ${ }^{23}$

The results for Australia are displayed in Figure 8. For the resource boom shock they show a similar pattern to Norway. Service sectors such as construction, transportation, and retail are particularly stimulated by the boom. However, in Australia, there are no low speed industries. Instead, several industries show evidence of actual decline in both value added and employment. In particular, industries such as hotel and food, business and to a certain extent manufacturing, contracts following the resource boom.

After a commodity price shock, most industries in Australia decline. Construction, real estate and public employment are the ones that are positively affected. These results are very much in line with the classical Dutch disease effects, where resources are moved out of tradable sectors and into non-tradables, and the tradable sector contracts.

Finally, a natural question arises after reading these results: Why does a commodity price shock affect the two commodity exporting countries so differently? One suggestion, discussed briefly above, is that offshore oil may demand complicated technical solutions, a process which generates positive knowledge externalities. This may have benefited petroleum producer Norway to a larger extent than mining abundant Australia.

Another possible answer to this question is the role of the governmental sector. As seen from Figures 7 and 8, employment in the public sector in both Norway and Australia responds positively to a commodity price shock. In Norway, value added in the public sector also increases, but falls slightly in Australia. Measuring the size of the public sector as the number of persons employed relative to the total population, we find that the governmental sector in Australia is only one fifth the size of Norway's. ${ }^{24}$ Thus, the governmental sector might work as a shock absorber in Norway, simply by virtue of its size. In addition, Norway has a generous welfare system that distributes wealth across the country, as well as a sovereign wealth fund, explicitly funded by petroleum revenues, which allows for extra spending of petroleum income when business cycles turn bad (as it does internationally after a commodity price shock).

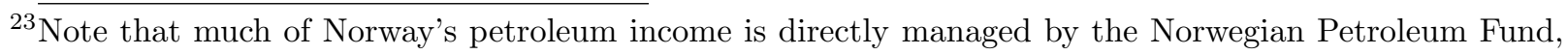
a specially created body with the express purpose of shielding the domestic economy from potential spending effects caused by the resource endowment. A fiscal rule, however, permits the government to spend approximately 4 percent of the fund (expected return) every year.

${ }^{24}$ The same holds if we compare the number of persons employed in this sector to the total number of persons employed. 


\section{Additional results and robustness}

We have estimated the model using a number of alternative data compositions and model specifications. As described in greater detail in Appendix C, the main conclusions of the paper are robust to all of these robustness checks. Below, we provide a brief summary.

First, the model specification is uncertain. The number of factors and lags employed in the model should be tested. We do this primarily by running a quasi-real-time forecasting experiment. The results reported in Appendix C.1 show that our benchmark model, outlined in Section 3.1, performs significantly better than simple univariate autoregressive processes. The benchmark specification is also among the best performing specifications and the best model specification over shorter forecasting horizons.

Second, global activity is not observed. As discussed in Appendix C.2, qualitatively, the results reported in Section 4 are not affected by changing how we measure this variable.

Third, we have estimated the models using a truncated estimation sample, ending in 2007:Q4. This alternative experiment excludes the financial crisis, and the period thereafter, from the sample. The importance of productivity spillovers and of separating between resource activity and commodity price shocks is prevalent even when the latter part of the estimation sample is excluded. In fact, for most of the main variables we look at, the benchmark responses and the responses obtained using the truncated sample are not significantly different from each other. If anything, for Australia, the results based on the truncated estimation sample are stronger, see Appendix C.3.

Finally, in Appendix C.4, we show that the results (for Norway) are robust, also after controlling for shocks to global oil supply.

We have also conducted a series of other robustness checks, for which details can be provided on request. In particular, as opposed to using US CPI to deflate the commodity prices, we have deflated the commodity prices by domestic CPI. The differences between the impulse response functions reported in Section 4 and these alternatives are basically undistinguishable. Further, the inclusion/exclusion of additional variables (to capture, e.g., wealth effects) will potentially also affect the factor estimates. Still, the main results are robust to estimating the models using only a subset of the variables in the observable $y_{t}$ vector, i.e., excluding time series for wages, investments, the terms of trade, stock prices, consumer and producer prices, and the short term interest rate. Lastly, as mentioned in Section 3.3, our results are robust to estimating the model using classical two-step estimation techniques, and as described in Section D.0.4, our results seem robust to different prior specifications.

\section{Conclusion}

This study examines the empirical validity of the classical Dutch disease theory versus a theory model that allows for direct productivity spillovers from the resource sector to both the traded and non-traded sector. Using Australia and Norway as representative case studies, we take the theory to the data by developing and estimating a Bayesian Dynamic Factor model, that includes separate activity factors for resource and non-resource sectors in addition to global activity and the real commodity price. In doing so, we explicitly 
identify and quantify windfall gains from a booming resource sector or higher commodity prices and the associated sectoral performance in the rest of the economy.

We have two main results: First, a booming resource sector has significant and positive productivity spillovers on non-resource sectors, effects that have not been captured in previous analyses. In particular, we find that the resource sector stimulates productivity and production in both Australia and Norway. Value added and employment increases moreover in the non-traded relative to the traded sectors, also suggesting a two-speed transmission phase. The most positively affected sectors are construction, business services and real estate. Second, windfall gains due to changes in the commodity price also stimulate the economy, particularly if the commodity price increase is associated with a boom in global demand. However, commodity price increases unrelated to global activity are less favourable, in part because of a substantial real exchange rate appreciation and reduced competitiveness. Still, value added and employment increase temporarily in Norway, mostly due to increased activity in the technologically intense service sectors and the boost in government spending. For Australia, the picture is more gloomy, as there is evidence of a Dutch disease effect with crowding out and an eventual decline in manufacturing.

These results emphasise the importance of distinguishing between windfall gains due to volume and price changes when analysing the Dutch disease hypothesis. To the best of our knowledge, this is the first paper to explicitly separate and quantify these two channels, while also allowing for explicit disturbances to world activity and the non-resource sectors.

\section{References}

Aastveit, K. A., H. C. Bjørnland, and L. A. Thorsrud (2014). What drives oil prices? Emerging versus developed economies. Journal of Applied Econometrics (forthcoming).

Aastveit, K. A., H. C. Bjørnland, and L. A. Thorsrud (2015). The world is not enough! Small open economies and regional dependence. Scandinavian Journal of Economics (forthcoming).

Bai, J. and S. Ng (2002). Determining the number of factors in approximate factor models. Econometrica $70(1), 191-221$.

Bai, J. and S. Ng (2013). Principal components estimation and identification of static factors. Journal of Econometrics 176(1), 18 - 29.

Bai, J. and P. Wang (2012). Identification and estimation of dynamic factor models. MPRA Paper 38434, University Library of Munich, Germany.

Barsky, R. B. and L. Kilian (2002). Do we really know that oil caused the great stagflation? A monetary alternative. In B. S. Bernanke and K. Rogoff (Eds.), NBER Macroeconomics Annual 2001, pp. 137-183. MIT Press: Cambridge, MA.

Bjørnland, H. C. (1998). The economic effects of North Sea oil on the manufacturing sector. Scottish Journal of Political Economy 45(5), 553-85. 
Bruno, M. and J. Sachs (1982). Energy and resource allocation: a dynamic model of the "Dutch Disease". The Review of Economic Studies 49(5), 845-859.

Carter, C. K. and R. Kohn (1994). On Gibbs Sampling for State Space Models. Biometrika 81(3), pp. 541-553.

Charnavoki, V. and J. Dolado (2014). The Effects of Global Shocks on Small CommodityExporting Economies: Lessons from Canada. American Economic Journal: Macroeconomics 6(2), 207-237.

Chen, Y.-c. and K. Rogoff (2003). Commodity currencies. Journal of International Economics 60, 133-160.

Corden, W. M. (1984). Booming sector and Dutch disease economics: Survey and consolidation. Oxford Economic Papers 36(3), 359-380.

Corden, W. M. and J. P. Neary (1982). Booming sector and de-industrialisation in a small open economy. The Economic Journal 92(368), 825-848.

Dungey, M., R. Fry-McKibbin, and V. Linehan (2014). Chinese resource demand and the natural resource supplier. Applied Economics 46(2), 167-178.

Eastwood, R. and A. J. Venables (1982). The macroeconomic implications of a resource discovery in an open economy. The Economic Journal 92(366), 285-299.

Furlanetto, F., S. Sarferaz, and F. Ravazzolo (2013). Business cycles in commodityexporting countries. Mimeo, Norges Bank.

Garton, P. (2008). The resources boom and the two-speed economy. Economic Roundup (3), 17.

Geweke, J. (1977). The dynamic factor analysis of economic time series. In latent Variables in Socio-economic Models. D.J. Aigner and A.S. Goldberger (Eds.).

Hamilton, J. D. (1983). Oil and the macroeconomy since world war II. Journal of Political Economy $91(2), 228-48$.

Hamilton, J. D. (2009). Causes and consequences of the oil shock of 2007-08. Brookings Papers on Economic Activity 40(1), 215-283.

Hamilton, J. D. and A. M. Herrera (2004). Oil Shocks and Aggregate Macroeconomic Behavior: The Role of Monetary Policy: Comment. Journal of Money, Credit and Banking 36(2), 265-86.

Hutchison, M. M. (1994). Manufacturing sector resiliency to energy booms: empirical evidence from Norway, the Netherlands, and the United Kingdom. Oxford Economic Papers 46, 311-329.

Ismail, K. (2010). The structural manifestation of the "Dutch Disease": The case of oil exporting countries. IMF Working Papers, 1-36. 
Kilian, L. (2009). Not all oil price shocks are alike: Disentangling demand and supply shocks in the crude oil market. American Economic Review 99(3), 1053-69.

Kim, C.-J. and C. R. Nelson (1999). State-Space Models with Regime Switching: Classical and Gibbs-Sampling Approaches with Applications (1 ed.), Volume 1. The MIT Press.

Kose, M. A., C. Otrok, and C. H. Whiteman (2003). International business cycles: World, region, and country-specific factors. American Economic Review 93(4), 1216-1239.

Krugman, P. (1987). The narrow moving band, the Dutch disease, and the competitive consequences of Mrs. Thatcher: Notes on trade in the presence of dynamic scale economies. Journal of development Economics 27(1), 41-55.

Lippi, F. and A. Nobili (2012). Oil and the macroeconomy: A quantitative structural analysis. Journal of the European Economic Association 10(5), 1059-1083.

Mumtaz, H., S. Simonelli, and P. Surico (2011). International comovements, business cycle and inflation: A historical perspective. Review of Economic Dynamics 14(1), 176-198.

Neary, J. P. and S. van Wijnbergen (1984). Can an oil discovery lead to a recession? A comment on Eastwood and Venables. The Economic Journal 94(374), 390-395.

Ratti, R. A. and M. Z. Hasan (2013). Oil Price Shocks and Volatility in Australian Stock Returns ? MPRA Paper 49043, University Library of Munich, Germany.

Spatafora, N. and A. M. Warner (1999). Macroeconomic and Sectoral Effects of Termsof-Trade Shocks - The Experience of the Oil-Exporting Developing Countries. IMF Working Papers 99/134, International Monetary Fund.

Stock, J. H. and M. W. Watson (2002). Macroeconomic forecasting using diffusion indexes. Journal of Business \& Economic Statistics 20(2), 147-62.

Stock, J. H. and M. W. Watson (2005). Implications of dynamic factor models for VAR analysis. NBER Working Papers 11467, National Bureau of Economic Research, Inc.

Torvik, R. (2001). Learning by doing and the Dutch disease. European Economic Review $45(2), 285-306$.

van Wijnbergen, S. (1984). The "Dutch Disease": a disease after all? The Economic Journal 94(373), 41-55. 


\section{Appendices}

\section{Appendix A Data and Sources}

\begin{tabular}{|c|c|c|c|c|c|c|}
\hline & \multirow[t]{2}{*}{ Sector } & \multicolumn{2}{|c|}{ Norway } & \multicolumn{2}{|c|}{ Australia } & \multirow[t]{2}{*}{ Variable in National Accounts } \\
\hline & & Mean & Std. & Mean & Std. & \\
\hline \multirow{14}{*}{$\frac{\hat{\theta}}{\mathrm{b}}$} & Res. extraction & -0.63 & 6.28 & 3.73 & 4.10 & Oil and natural gas extraction/mining \\
\hline & Res. service & 6.89 & 25.65 & 4.25 & 12.84 & Service activities in oil and gas/mining \\
\hline & Manufacturing & 1.56 & 3.53 & 1.03 & 3.44 & Manufacturing \\
\hline & Construction & 3.04 & 5.02 & 4.37 & 7.44 & Construction \\
\hline & Retail & 4.39 & 3.46 & 3.64 & 2.18 & Wholesale and retail trade \\
\hline & Transp. ocean & -5.32 & 16.22 & & & Ocean transport \\
\hline & Transportation & 1.03 & 5.26 & 3.66 & 3.25 & Transport activities excl. ocean transport \\
\hline & Hotel and food & 1.76 & 4.84 & 2.70 & 3.80 & Accommodation and food service activities \\
\hline & Financial & 3.90 & 7.88 & 4.70 & 3.77 & Financial and insurance activities \\
\hline & Real estate & 9.20 & 10.81 & 2.66 & 4.46 & Real estate activities \\
\hline & Scientific & 4.12 & 4.75 & 4.96 & 4.43 & Professional, scientific and technical activities \\
\hline & Business & 6.79 & 6.91 & 3.49 & 5.29 & Administrative and support service activities \\
\hline & Non-resource & 2.79 & 1.95 & 3.12 & 1.73 & Total excl. oil and gas extraction/mining \\
\hline & Public & 1.64 & 1.46 & 2.65 & 2.89 & General government \\
\hline \multirow{14}{*}{ 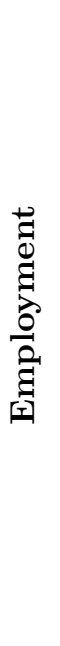 } & Res. extraction & 2.43 & 5.32 & 4.69 & 9.98 & \multirow{14}{*}{ See above } \\
\hline & Res. service & 11.14 & 14.30 & & & \\
\hline & Manufacturing & -0.59 & 3.35 & -0.57 & 3.14 & \\
\hline & Construction & 3.95 & 4.05 & 2.81 & 4.77 & \\
\hline & Retail & 1.28 & 1.99 & 1.72 & 2.75 & \\
\hline & Transp. ocean & 0.91 & 2.79 & & & \\
\hline & Transportation & 0.70 & 2.22 & 1.50 & 4.36 & \\
\hline & Hotel and food & 1.10 & 2.70 & 2.52 & 3.79 & \\
\hline & Financial & -0.13 & 2.92 & 0.85 & 4.47 & \\
\hline & Real estate & 5.98 & 6.61 & 2.53 & 7.25 & \\
\hline & Scientific & 3.61 & 3.75 & 4.00 & 5.12 & \\
\hline & Business & 5.66 & 6.32 & 3.65 & 6.36 & \\
\hline & Non-resource & 1.33 & 1.54 & 1.66 & 1.70 & \\
\hline & Public & 1.33 & 0.92 & 2.29 & 4.25 & \\
\hline \multirow{6}{*}{$\begin{array}{l}\dot{\vec{d}} \\
\frac{\overrightarrow{0}}{0}\end{array}$} & Wages resource & 9.90 & 6.87 & 5.13 & 3.00 & Wages petroleum sector/mining \\
\hline & Wages public & 6.04 & 1.77 & 4.16 & 1.40 & Wages public \\
\hline & Wages non-res. & 6.06 & 2.38 & 4.20 & 1.55 & Total excl. wages to petroleum sector/mining \\
\hline & Invest. res. & 4.52 & 22.62 & 12.01 & 25.47 & Investment petroleum sector/mining \\
\hline & Invest. non-res. & 4.06 & 8.60 & 5.60 & 12.43 & Total excl. invest. in petroleum sector/mining \\
\hline & Exchange rate & 0.57 & 4.79 & 0.11 & 2.05 & BIS effective exchange rate index, broad basket \\
\hline \multirow{2}{*}{$\dot{\Xi}$} & World activity & 2.78 & 1.90 & 4.54 & 2.10 & See text, Section 3.4 \\
\hline & Com. Price & 9.01 & 33.11 & 2.89 & 15.64 & Commodity price. See text, Section 3.4 \\
\hline
\end{tabular}

Note: The table lists the core variables used in the benchmark model. All activity, investment, wages and employment series are collected from the Quarterly National Accounts database of Statistics Norway and Statistics Australia, respectively. The international series are from Datastream. The real exchange rates are from the Bank of International Settlements (BIS). The moments are computed based on the transformed variables, i.e. $\left.\log \left(x_{i, t}\right)-\log \left(x_{i, t-4}\right)\right) \times 100$. See Section 3.4 for the details. 


\section{Appendix B Additional figures and tables}

Table 4. Correlations with commodity price

\begin{tabular}{|c|c|c|c|c|}
\hline \multirow[t]{2}{*}{ Country } & \multicolumn{4}{|l|}{ Variable } \\
\hline & $\mathrm{Y}$ & YR & M & ME \\
\hline Norway & $0.28(0.02)$ & $0.08(0.53)$ & $0.38(0.00)$ & $-0.09(0.47)$ \\
\hline Australia & $0.14(0.21)$ & $0.05(0.63)$ & $0.23(0.03)$ & $-0.09(0.41)$ \\
\hline
\end{tabular}

Note: The table reports the contemporaneous correlations coefficients (p-value in parenthesis) between commodity prices and non-resource GDP (y), resource GDP (YR), value added in Manufacturing (M), and employment in Manufacturing (ME). The raw data is measured as four-quarter logarithmic changes. The sample is 1991:Q1 - 2012:Q4 and 1996:Q1 - 2012:Q4, for Australia and Norway, respectively

Figure 9. Global impulse responses

Model for Norway

Global activity Real oil price
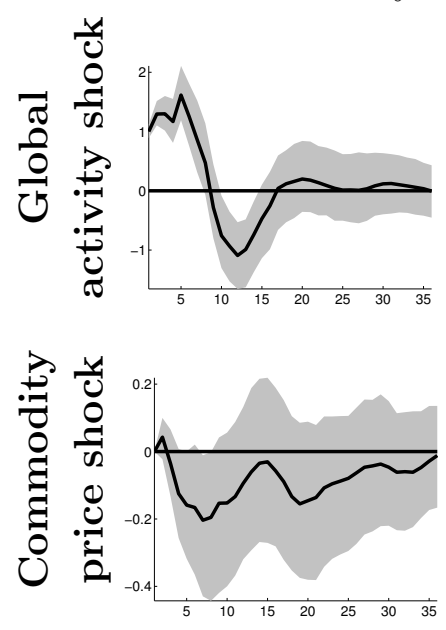
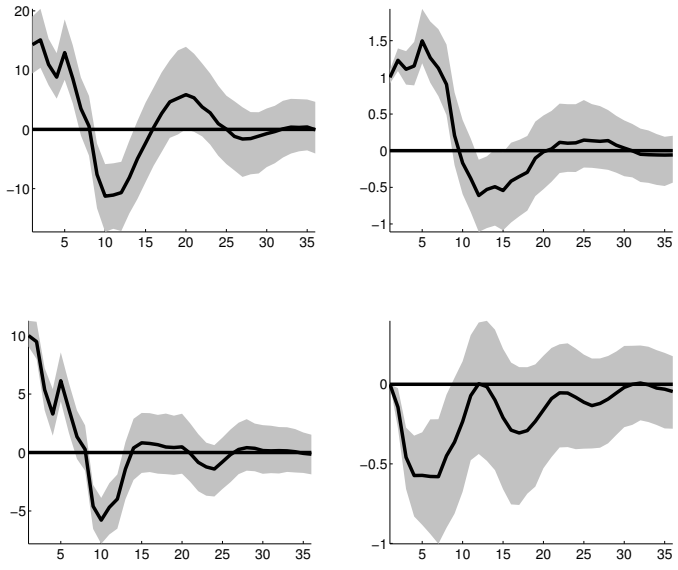

Model for Australia

Global activity Real commodity price
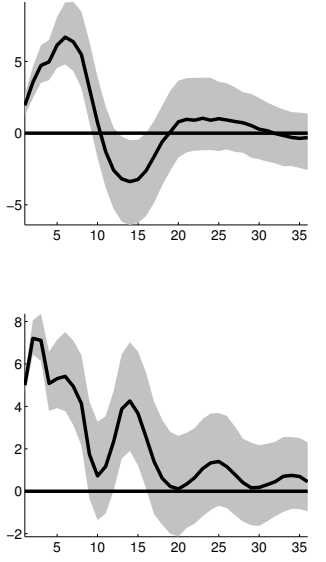

Note: The plots display impulse responses in levels. The Global activity shock is normalized to increase global activity by 1 percent, while the commodity price shock is normalized to increase the commodity price index and the real price of oil with 5 and 10 percent, respectively. The black solid lines are median estimates. The grey shaded areas are 68 percent probability bands 
Figure 10. Norway and Australia. Global activity shock and domestic responses

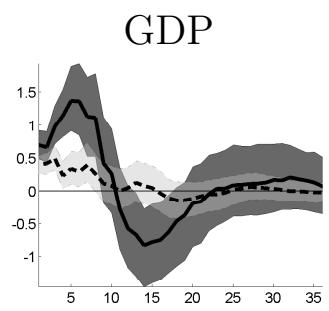

Real exchange rate

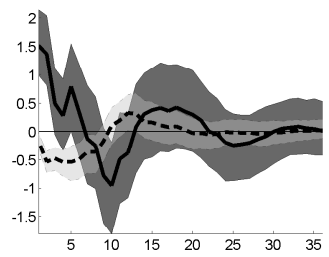

Productivity

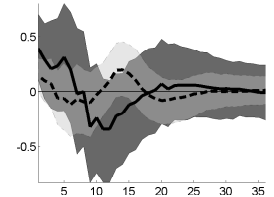

CPI

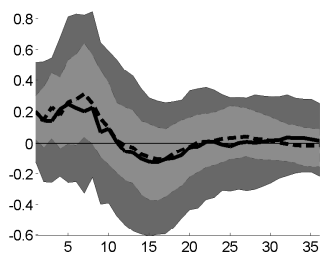

Investment

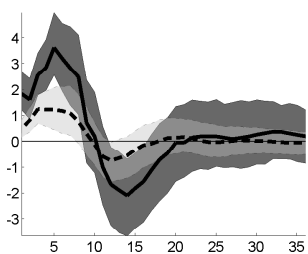

Stock price

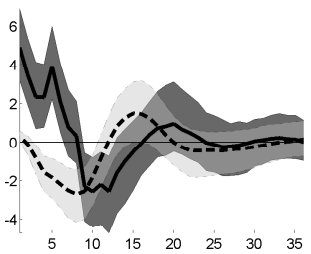

Employment

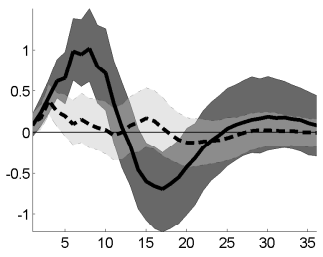

Terms of trade

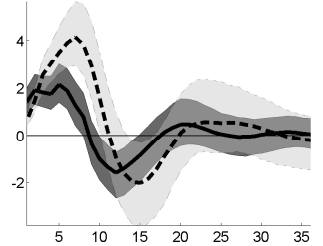

Note: The global activity shock is normalized to increase the global activity factor by 1 percent. In each plot, Norway (Australia) is the solid (dotted) line with the associated dark (light) grey probability bands. See also the note to Figure 4

Figure 11. Norway and Australia. Domestic activity shock and domestic responses

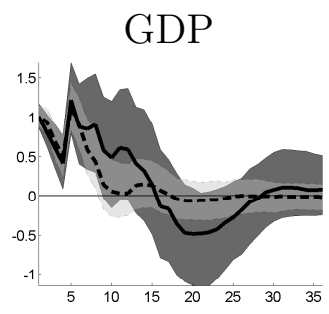

Real exchange rate

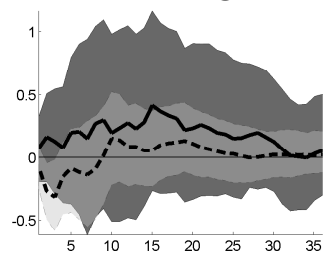

Productivity

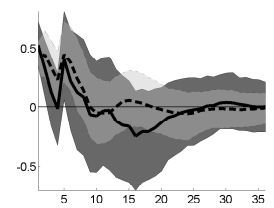

CPI

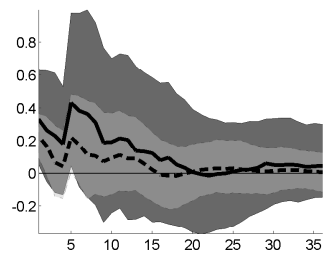

Investment

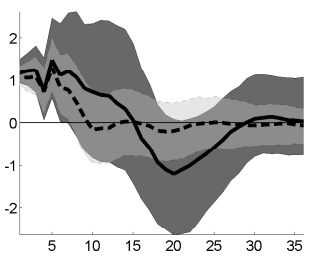

Stock price

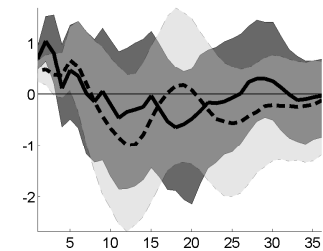

Employment

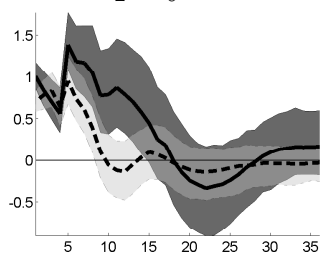

Terms of trade

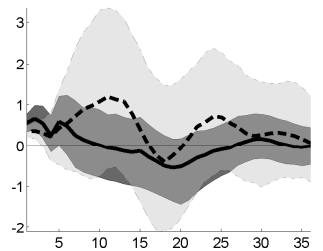

Note: The domestic activity shock is normalized to increase the domestic activity factor in each country by 1 percent. In each plot, Norway (Australia) is the solid (dotted) line with the associated dark (light) grey probability bands. See also the note to Figure 4 
Table 5. Variance decompositions: Non-resource Sectors

\begin{tabular}{|c|c|c|c|c|c|c|}
\hline & & & Shock & & & \\
\hline & Variable & Sector & $\begin{array}{c}\text { Resource } \\
\text { activity }\end{array}$ & $\begin{array}{c}\text { Commodity } \\
\text { price }\end{array}$ & $\begin{array}{c}\text { Global } \\
\text { activity }\end{array}$ & $\begin{array}{c}\text { Domestic } \\
\text { activity }\end{array}$ \\
\hline & & Horizon & 4,8 & 4,8 & 4,8 & 4,8 \\
\hline & & Construction & $0.24,0.34$ & $0.02,0.01$ & $0.57,0.54$ & $0.16,0.11$ \\
\hline & & Business & $0.24,0.35$ & $0.13,0.05$ & $0.51,0.50$ & $0.12,0.10$ \\
\hline & & Hotel and food & $0.06,0.18$ & $0.09,0.03$ & $0.67,0.64$ & $0.17,0.14$ \\
\hline & & Retail & $0.66,0.72$ & $0.02,0.03$ & $0.27,0.22$ & $0.05,0.03$ \\
\hline & $C D P$ & Transportation & $0.14,0.24$ & $0.13,0.06$ & $0.67,0.65$ & $0.06,0.06$ \\
\hline & GDI & Financial & $0.33,0.46$ & $0.45,0.33$ & $0.20,0.17$ & $0.02,0.04$ \\
\hline & & Scientific & $0.06,0.04$ & $0.42,0.27$ & $0.44,0.58$ & $0.08,0.11$ \\
\hline & & Real estate & $0.08,0.11$ & $0.78,0.74$ & $0.14,0.15$ & $0.00,0.00$ \\
\hline & & Manufacturing & $0.06,0.11$ & $0.22,0.12$ & $0.69,0.74$ & $0.03,0.03$ \\
\hline$\sum_{i=1}^{\infty}$ & & Public & $0.03,0.02$ & $0.49,0.40$ & $0.07,0.12$ & $0.41,0.46$ \\
\hline & & Construction & $0.21,0.33$ & $0.15,0.08$ & $0.50,0.47$ & $0.14,0.11$ \\
\hline & & Business & $0.07,0.13$ & $0.11,0.04$ & $0.65,0.68$ & $0.17,0.14$ \\
\hline & & Hotel and food & $0.26,0.12$ & $0.13,0.12$ & $0.34,0.48$ & $0.27,0.29$ \\
\hline & & Retail & $0.37,0.39$ & $0.05,0.02$ & $0.37,0.44$ & $0.22,0.15$ \\
\hline & Fmployment & Transportation & $0.34,0.16$ & $0.13,0.09$ & $0.05,0.27$ & $0.49,0.48$ \\
\hline & сітріоунеп & Financial & $0.31,0.33$ & $0.15,0.11$ & $0.53,0.51$ & $0.02,0.05$ \\
\hline & & Scientific & $0.23,0.10$ & $0.02,0.06$ & $0.23,0.45$ & $0.52,0.39$ \\
\hline & & Real estate & $0.17,0.19$ & $0.17,0.05$ & $0.51,0.62$ & $0.15,0.13$ \\
\hline & & Manufacturing & $0.09,0.07$ & $0.15,0.14$ & $0.26,0.40$ & $0.50,0.39$ \\
\hline & & Public & $0.28,0.16$ & $0.19,0.18$ & $0.08,0.15$ & $0.45,0.51$ \\
\hline & & Construction & $0.31,0.41$ & $0.22,0.13$ & $0.13,0.11$ & $0.34,0.36$ \\
\hline & & Business & $0.04,0.08$ & $0.20,0.25$ & $0.57,0.48$ & $0.19,0.19$ \\
\hline & & Hotel and food & $0.21,0.20$ & $0.02,0.17$ & $0.23,0.18$ & $0.54,0.46$ \\
\hline & & Retail & $0.13,0.13$ & $0.19,0.29$ & $0.08,0.04$ & $0.60,0.54$ \\
\hline & CDP & Transportation & $0.19,0.13$ & $0.03,0.07$ & $0.56,0.56$ & $0.22,0.24$ \\
\hline & & Financial & $0.06,0.06$ & $0.44,0.57$ & $0.30,0.20$ & $0.20,0.17$ \\
\hline & & Scientific & $0.85,0.78$ & $0.01,0.09$ & $0.01,0.05$ & $0.13,0.08$ \\
\hline & & Real estate & $0.10,0.12$ & $0.23,0.19$ & $0.08,0.07$ & $0.60,0.62$ \\
\hline . & & Manufacturing & $0.19,0.10$ & $0.31,0.43$ & $0.47,0.39$ & $0.03,0.08$ \\
\hline$\stackrel{5}{7}$ & & Public & $0.29,0.30$ & $0.31,0.24$ & $0.00,0.06$ & $0.39,0.40$ \\
\hline 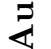 & & Construction & $0.15,0.13$ & $0.23,0.38$ & $0.14,0.06$ & $0.48,0.42$ \\
\hline & & Business & $0.75,0.61$ & $0.07,0.26$ & $0.01,0.04$ & $0.17,0.09$ \\
\hline & & Hotel and food & $0.59,0.48$ & $0.14,0.36$ & $0.13,0.07$ & $0.14,0.09$ \\
\hline & & Retail & $0.23,0.16$ & $0.14,0.28$ & $0.16,0.12$ & $0.47,0.44$ \\
\hline & Fmplorment & Transportation & $0.16,0.08$ & $0.23,0.21$ & $0.52,0.59$ & $0.09,0.12$ \\
\hline & Бөшріоу петь & Financial & $0.07,0.05$ & $0.20,0.09$ & $0.59,0.77$ & $0.14,0.10$ \\
\hline & & Scientific & $0.41,0.40$ & $0.21,0.27$ & $0.20,0.20$ & $0.18,0.14$ \\
\hline & & Real estate & $0.06,0.19$ & $0.56,0.52$ & $0.34,0.24$ & $0.04,0.04$ \\
\hline & & Manufacturing & $0.03,0.02$ & $0.33,0.47$ & $0.38,0.30$ & $0.26,0.21$ \\
\hline & & Public & $0.14,0.11$ & $0.57,0.45$ & $0.28,0.43$ & $0.00,0.01$ \\
\hline
\end{tabular}

Note: Each row-column intersection reports median variance decompositions for horizons 4 (left) and 8 (right) 


\section{Appendix C Robustness}

\section{C.1 Model specification}

The correct model specification is uncertain. For both the Australian and the Norwegian data sets, different test statistics, see Bai and Ng (2002), suggest between 3 and 8 static factors. 4 factors explain approximately 45 and 60 percent of the variation in the dataset for Australia and Norway, respectively. Including an additional 4 static factors increases the variance explained by modestly 15 percent. Although informative, the tests for the number of static factors are far from conclusive.

To fully test our preferred model specification relative to alternative specifications, we run a quasi-real-time forecasting experiment. The experiment is conducted as follows: For the sample period from 1991:Q1 (1996:Q1) - 2012:Q4, we estimate the BDFM with different lag specifications. In particular, we allow for up to 2 lags of the vector of factors in the observation equation $(s=0, \ldots, 2)$. For each lag specification we also estimate the model with and without autocorrelated idiosyncratic errors $(l=0,1)$. Ultimately, this yields 6 different specifications. Lastly, for each of these combinations we estimate the model with 4 and 8 lags in the transition equation $(h=4,8)$.

We compute the model's out of sample forecasting performance over the period from 1991:Q2 (1996:Q2) - 2012:Q4. The performance is scored by root mean forecasting errors (RMSE) and $\log$ scores (logScore). ${ }^{25}$ The forecasting experiment is quasi-real-time, as we do not re-estimate the models for each new vintage of data we forecast, and we also do not use real-time vintage data when estimating the models or in the evaluation of forecasting performance. Thus, the distribution of the model parameters used to forecast is assumed to be constant throughout the evaluation period. For our purpose, which is to make comparison among nested structural models, this is an innocuous assumption. Furthermore, an advantage of our quasi-real-time forecasting experiment, as opposed to a real-time forecasting experiment, is that we can evaluate the forecasting performance over a much longer sample. That is, in a real-time experiment, we would have to re-estimate the models for each new vintage and use a substantial part of the sample to estimate the initial parameter distributions.

Table 6 reports the results. ${ }^{26}$ The top and bottom panels report the results for Norway and Australia, respectively. At the two step ahead horizon, and evaluated across all variables, our preferred model specification, BDFM s(2)a(1) (denoted Benchmark in the table), performs substantially better than any other model specification. For Norway (Australia), and for 27 (20) and 28 (25) out of 44 (42) variables, the Benchmark model performs best in terms of RMSE and average logScore, respectively. At the four step ahead horizon, the ranking of the different model specifications changes, and for both the

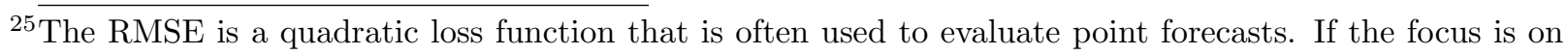
the whole forecast distribution, the RMSE is not appropriate and log scoring is a better metric. The logScore is the logarithm of the probability density function evaluated at the out-turn of the forecast. As such it provides an intuitive measure of density fit.

${ }^{26}$ To save space, we do not report the results for forecasting horizons 1 and 3 , and for the models estimated with $h=4$. The general conclusions reported in Table 6 do not change for these additional horizons and specifications. 
Table 6. Forecast performance

\begin{tabular}{|c|c|c|c|c|c|c|c|}
\hline \multirow[t]{2}{*}{ Country } & \multirow[t]{2}{*}{ Horizon } & \multirow[t]{2}{*}{ Model } & \multicolumn{4}{|l|}{ Variable } & \multirow{2}{*}{$\begin{array}{l}\text { All } \\
\text { variables }\end{array}$} \\
\hline & & & $\mathbf{Y}$ & $\mathbf{E}$ & $\mathbf{I}$ & W & \\
\hline \multirow{14}{*}{ 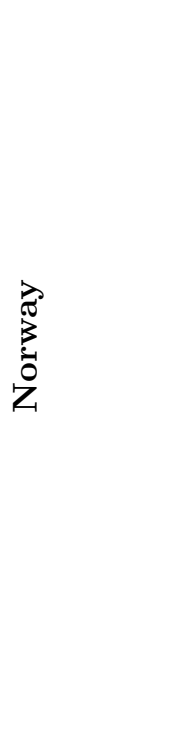 } & 2 & $\operatorname{BDFM} \mathrm{s}(0) \mathrm{a}(0)$ & $0.85,0.94$ & $0.80,1.04$ & $0.98,0.98$ & $0.92,1.01$ & 0,2 \\
\hline & & BDFM $\mathrm{s}(1) \mathrm{a}(0)$ & $0.96,0.99$ & $0.86,1.02$ & $0.99,0.99$ & $0.99,1.01$ & 0,1 \\
\hline & & BDFM $\mathrm{s}(2) \mathrm{a}(0)$ & $0.98,1.00$ & $0.88,1.00$ & $1.01,1.01$ & $1.10,1.01$ & 9,7 \\
\hline & & $\operatorname{BDFM} \mathrm{s}(0) \mathrm{a}(1)$ & $0.86,0.93$ & $0.86,1.01$ & $0.98,0.99$ & $0.88,1.00$ & 7,7 \\
\hline & & BDFM $\mathrm{s}(1) \mathrm{a}(1)$ & $1.00,1.00$ & $1.00,1.01$ & $0.97,0.98$ & $0.95,0.99$ & 2,0 \\
\hline & & $\operatorname{AR}(1)$ & $0.57,0.82$ & $0.38,0.82$ & $0.84,0.86$ & $0.41,0.72$ & 0,0 \\
\hline & & Benchmark & $0.01,3.20$ & $0.00,3.68$ & $0.06,1.31$ & $0.01,3.20$ & 27,28 \\
\hline & 4 & $\operatorname{BDFM} \mathrm{s}(0) \mathrm{a}(0)$ & $0.97,0.98$ & $0.91,1.05$ & $1.01,1.01$ & $0.93,1.03$ & 2,7 \\
\hline & & BDFM s(1)a(0) & $0.99,0.98$ & $0.93,1.04$ & $1.02,1.02$ & $1.02,1.04$ & 1,7 \\
\hline & & $\operatorname{BDFM} \mathrm{s}(2) \mathrm{a}(0)$ & $1.00,0.99$ & $0.96,1.02$ & $1.05,1.05$ & $1.12,1.03$ & 28,19 \\
\hline & & $\operatorname{BDFM} \mathrm{s}(0) \mathrm{a}(1)$ & $0.95,0.95$ & $0.95,1.01$ & $0.97,0.97$ & $0.84,1.00$ & 3,5 \\
\hline & & BDFM $\mathrm{s}(1) \mathrm{a}(1)$ & $0.99,0.99$ & $0.98,1.01$ & $0.96,0.96$ & $0.93,1.00$ & 0,1 \\
\hline & & $\operatorname{AR}(1)$ & $0.56,0.68$ & $0.39,0.50$ & $0.83,0.79$ & $0.31,0.39$ & 0,0 \\
\hline & & Benchmark & $0.01,2.94$ & $0.01,3.43$ & $0.07,1.20$ & $0.01,3.02$ & 11,6 \\
\hline \multirow{14}{*}{ 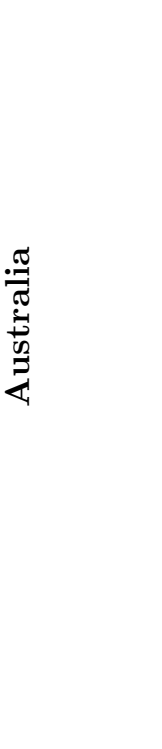 } & 2 & $\operatorname{BDFM} \mathrm{s}(0) \mathrm{a}(0)$ & $0.97,0.98$ & $0.92,0.97$ & $0.93,0.96$ & $0.93,0.96$ & 1,0 \\
\hline & & BDFM s(1)a(0) & $1.02,1.00$ & $0.89,0.96$ & $0.87,0.87$ & $0.94,0.96$ & 1,0 \\
\hline & & $\operatorname{BDFM} \mathrm{s}(2) \mathrm{a}(0)$ & $1.01,1.00$ & $0.88,0.95$ & $0.89,0.89$ & $0.97,0.97$ & 7,6 \\
\hline & & $\operatorname{BDFM} \mathrm{s}(0) \mathrm{a}(1)$ & $0.97,0.96$ & $1.03,1.00$ & $1.00,1.01$ & $1.01,1.00$ & 10,11 \\
\hline & & BDFM $\mathrm{s}(1) \mathrm{a}(1)$ & $1.01,1.00$ & $1.01,1.00$ & $1.00,1.01$ & $0.98,0.99$ & 3,0 \\
\hline & & $\operatorname{AR}(1)$ & $0.72,0.84$ & $0.67,0.81$ & $0.95,0.89$ & $0.80,0.90$ & 0,0 \\
\hline & & Benchmark & $0.01,3.05$ & $0.01,3.20$ & $0.10,0.89$ & $0.01,3.23$ & 20,25 \\
\hline & 4 & $\operatorname{BDFM} \mathrm{s}(0) \mathrm{a}(0)$ & $0.96,0.97$ & $1.01,1.00$ & $1.09,1.30$ & $0.95,0.97$ & 8,10 \\
\hline & & $\operatorname{BDFM} \mathrm{s}(1) \mathrm{a}(0)$ & $0.99,0.99$ & $0.98,0.99$ & $1.03,1.23$ & $0.97,0.98$ & 1,2 \\
\hline & & $\operatorname{BDFM} \mathrm{s}(2) \mathrm{a}(0)$ & $0.99,0.99$ & $0.97,0.99$ & $1.05,1.23$ & $0.99,0.98$ & 21,19 \\
\hline & & $\operatorname{BDFM} \mathrm{s}(0) \mathrm{a}(1)$ & $0.99,0.95$ & $1.06,1.02$ & $1.00,1.02$ & $0.95,0.99$ & 6,6 \\
\hline & & BDFM $\mathrm{s}(1) \mathrm{a}(1)$ & $0.99,0.99$ & $1.01,1.01$ & $1.00,1.01$ & $0.97,0.99$ & 0,0 \\
\hline & & $\operatorname{AR}(1)$ & $0.56,0.64$ & $0.62,0.52$ & $0.88,0.53$ & $0.60,0.74$ & 0,0 \\
\hline & & Benchmark & $0.01,2.97$ & $0.01,2.93$ & $0.11,0.65$ & $0.01,3.20$ & 6,5 \\
\hline
\end{tabular}

Note: The table reports quasi out-of-sample forecasting results. The Benchmark is BDFM s(2)a(1) model (main model used in the paper). $s($ ) denotes the number of lags used for the factors in the observation equation, a() denotes the number of lags used for the idiosyncratic AR process. The abbreviations $Y, E I$ and $W$ are respectively GDP, employment, investment and wages in the non-resource sectors. AR(1) is a univariate AR(1) models for each variable. For each model, variable, and horizon the reported numbers are relative RMSE (left) and (negative) average logScore (right) scores, i.e. $\frac{B D F M s(2) a(1)_{h, v}}{M_{h, v}^{i}}$, where $M^{i}$ is one of the alternative model specifications, with $i=1, \cdots, 6, v=(Y, E, I, W)$, and $h$ is the forecasting horizon. Thus, a number smaller than one indicates the Benchmark model performs better than the alternative. For the BDFM s(2)a(1) model the numbers reported are the actual scores. The numbers in the last column show how many times model $i$, at horizon $h$, is ranked as the best model when the performance across all variables $v=1, \cdots, N$ is evaluated. 
Australian and Norwegian data sets, the BDFM s(2)a(0) model receives a better score than the other models in approximately 50 percent of the cases.

Generally, the forecasting performance increases with the number of lagged factors, while the inclusion of autocorrelated idiosyncratic errors seems to be less important for forecasts four quarters into the future. Viewed from a bias-variance trade-off perspective, this is intuitive. The richer specified Benchmark model has a better in sample fit, thus a lower bias, but may have a higher degree of variance. At longer forecasting horizons, this reduces forecast accuracy.

Bai and Wang (2012) show in a simulation study that specifying a BDFM without autocorrelated idiosyncratic errors, although the underlying data generating process has this feature, generally produces estimates of the latent factors that are less reliable than specifying a BDFM with autocorrelated idiosyncratic errors, despite the underlying data generating process lacking this feature. Thus, although the BDFM s(2)a(0) specification also performs well in terms of forecasting, we prefer the Benchmark model.

Evaluating the Benchmark model with $h=4$ relative to $h=8$ (results not reported in the table) we observe that the logScore is generally higher, indicating a better density fit, while the RMSE is essentially unchanged. However, as documented in Hamilton and Herrera (2004), when modelling the oil market, an overly restrictive lag structure might lead to misleading results. Accordingly, we report the results for the $h=8$ specification.

For many variables, e.g., GDP, simple time series models such as AR processes are often difficult to outperform with respect to forecasting performance. We therefore also compare the performance of the Benchmark model with that of a simple univariate AR(1) model. ${ }^{27}$ As can be seen from Table 6 , the forecasting performance of the dynamic factor model is substantially better than the AR(1). For example, for GDP (Y) at horizon 2, and evaluated using the RMSE, the performance of the Benchmark model is over 40 and 20 percent better than the AR(1) model for Norway and Australia, respectively. For employment (E), the Benchmark model is even more superior, with an improvement of over 60 and 30 percent relative to the $\mathrm{AR}(1)$ model.

In summary, the results reported in table 6 support our Benchmark model specification. The highly parametrized, and structural, factor model is also superior to simple AR(1) models for most variables and at most horizons. As such, our findings confirm a voluminous literature documenting the usefulness of factor models for forecasting, see, e.g., Stock and Watson (2002).

\section{C.2 What is global activity?}

As described in Section 3.4, we construct the observable world activity series based on the mean across 8 different countries. These countries are not chosen ad-hoc: they represent Australia and Norway's most important trading partners and the largest economies in the world. Importantly, our main results are robust to different world activity approximations, with one exception. China should not be excluded from the set. As shown in Aastveit et al. (2014), growth in emerging economies (here represented by China), has been fundamental

${ }^{27}$ We estimate one $\operatorname{AR}(1)$ model for each observable variable, $v=1, \cdots, N$, and conduct the same quasireal-time forecasting experiment as described above. 
in explaining the surge in oil prices over the last two decades. To capture this important driver of the oil market, China should not be excluded from the construction of the global activity factor. Including or excluding countries other than the US and China from the international set, does not alter our main conclusions.

That being said, world activity is not an observable variable. Thus, we also attempted to estimate the world activity factor as a latent factor in the same manner as we estimate the latent oil and domestic activity factors. This became difficult. Employing reasonable uninformative priors, and without restrictions on the hyper-parameters, the model is not able to distinguish the different factors from each other in any meaningful manner. Thus, our approach of approximating world activity as the mean across 8 different countries could be regarded as employing more informative priors and placing restrictions on the hyper-parameters. Ideally, this should have been performed within the modelling framework. However, as the extraction of the world activity factor is not the main research question of this study, we have not pursued the issue further.

\section{C.3 Does the financial crisis matter?}

As seen in Figure 3, the financial crisis erupting early in 2008 caused large movements in the global activity factors and in the commodity prices. One might worry that this episode, and the periods thereafter, affect our main conclusions. They do not. Figures 12 and 13 show that the importance of productivity spillovers and separating between resource activity and commodity price shocks are prevalent even when excluding the later part of the estimation sample. The figures compare, for Norway and Australia, respectively, the benchmark results from the paper, with alternative results constructed based on a truncated estimation sample, ending in 2007:Q4. ${ }^{28}$

For Norway, see Figure 12, comparing the results from the original model with the alternative, we see that none of the main impulse responses seem to be significantly different from each other. If anything, the effect of a 1 percent unexpected resource activity shock leads to a slightly less persistent positive response in GDP and employment, while a 10 percent unexpected increase in the real price of oil causes a somewhat larger negative effect on productivity after 8-12 quarters, but a somewhat stronger positive response in GDP at the shorter horizons. Irrespective of which sample we use, the real exchange rate appreciates significantly after a commodity price shock.

For Australia, see Figure 13, the results for the resource activity shock are stronger when the sample is truncated compared to the benchmark results. That is, a 1 percent resource activity shock leads to a more positive response in both GDP, productivity and employment. Moreover, the responses seem to be significantly different from each other for at least GDP and employment. Finally, a 5 percent unexpected increase in the real commodity price index still leads to a fall in productivity, consistent with the benchmark

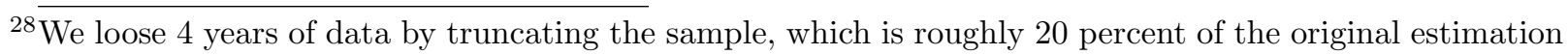
samples. As the sample lengths are already short for models of our size we treat the factors as observables in this alternative experiment, but re-estimate the parameters of the model. For the same reason we also reduce the lag length of the transition equation to 4 . Uncertainty bands are simulated using residual bootstraps, where parameter uncertainties in both the observation and transition equation are accounted for.
} 
Figure 12. Norway: Excluding the financial crisis. Resource gifts, commodity price shocks, and domestic responses

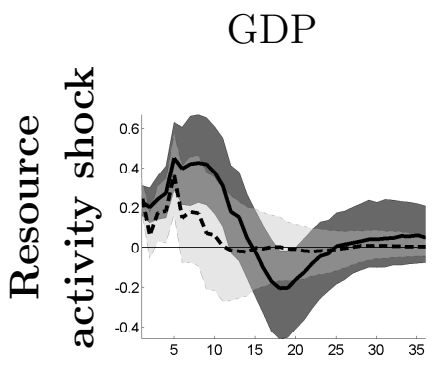

Productivity

$$
\text { Employment }
$$

Real exchange rate
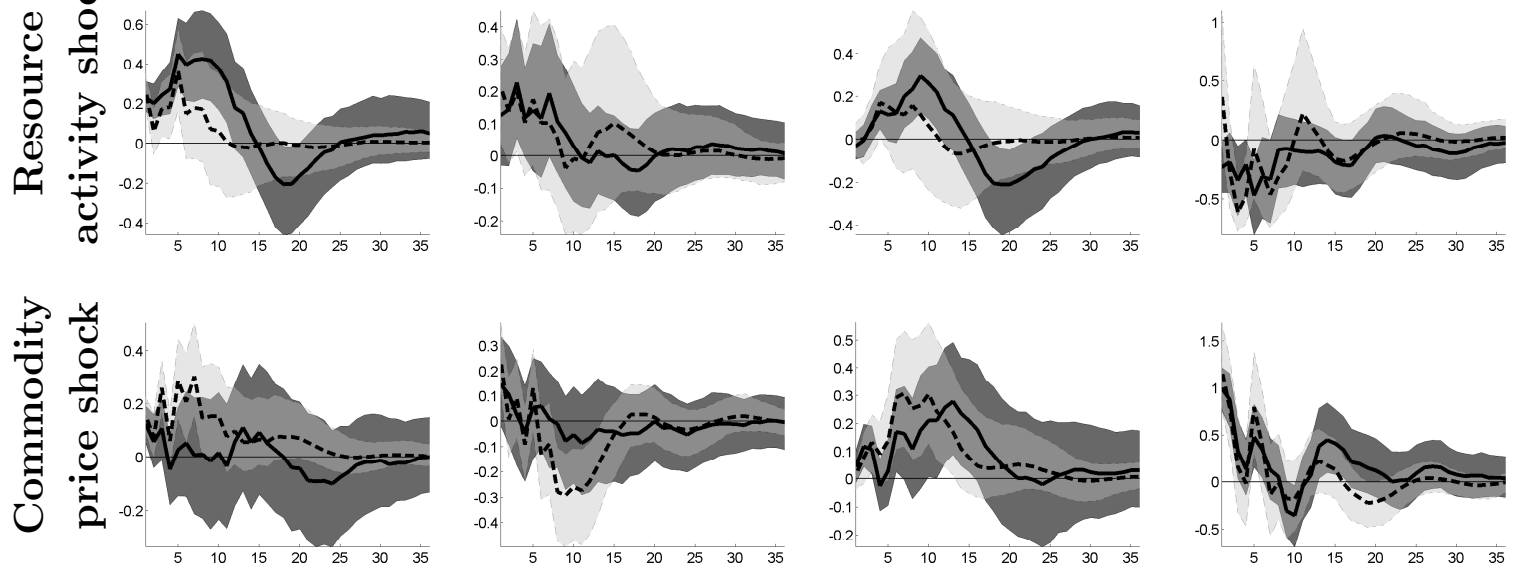

Note: In each plot, the original model (short sample model) is the solid (dotted) line with the associated dark (light) grey probability bands. The responses are displayed in levels of the variables. The resource boom shock (commodity price shock) is normalized to increase the resource activity factor (commodity price) by 1 (10) percent. The shaded areas (dark grey) represent 68 percent probability bands, while the lines (solid and dotted) are median estimates

Figure 13. Australia: Excluding the financial crisis. Resource gifts, commodity price shocks, and domestic responses

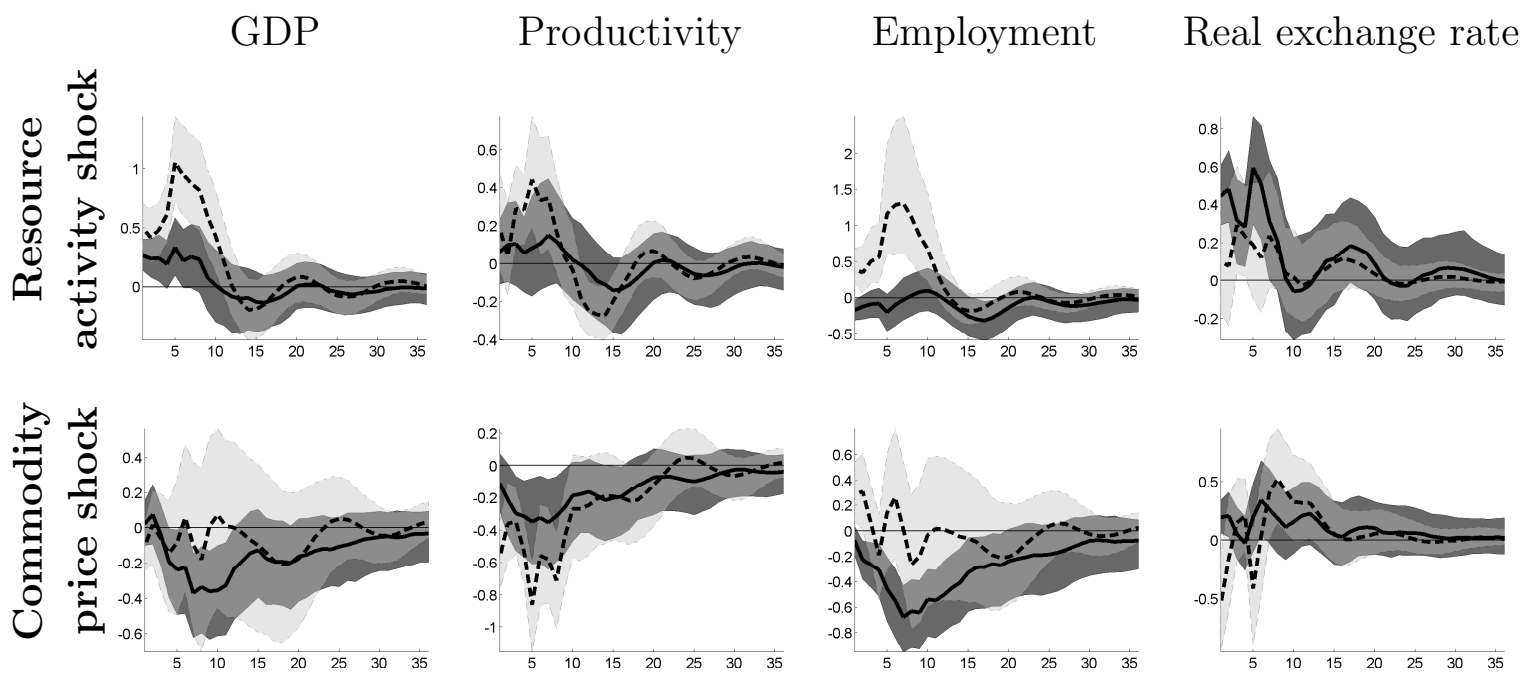

Note: The commodity price shock is normalized to increase the commodity price by 5 percent. See also the note to Figure 12

results, while the responses in GDP and employment are insignificant when using the shorter sample. 


\section{C.4 Including global oil supply}

Consistent with recent work in the oil market literature, see, e.g., Kilian (2009), Lippi and Nobili (2012) and Aastveit et al. (2014), we do not treat commodity prices as exogenous to the rest of the macro economy. Any unexpected news regarding global activity is assumed to affect real commodity prices contemporaneously. However, in our benchmark model, we depart from Kilian (2009) by not explicitly identifying a global commodity supply shock. For this reason we can not separate between supply and demand shocks in the oil market. There are two primary reasons why we do this: First, we want to keep the empirical model as parsimonious as possible, and second, for Australia it is not easy to construct a variable describing global supply of commodities.

Still, in Figure 14 we show that our main results for Norway are robust also after controlling for global oil supply. That is, we augment the benchmark model with global oil production, measured as the four quarter change in world crude oil production (millions of barrels per day), and like in Kilian (2009), we order this variable as the first variable in the transition equation. In the figure we compare the main impulse responses from this augmented model to the results obtained from the benchmark model. Following the interpretation given by Kilian (2009), the commodity price shock can now be interpreted as a precautionary demand shock, associated with, e.g., market fears of future oil supply disruptions.

As seen from the figure, the responses in GDP, employment and the real exchange rate are basically unchanged compared to the benchmark model. This is not surprising. As shown in Kilian (2009), and a range of subsequent papers, oil market supply shocks explain a trivial fraction of the total variance in the price of oil, and do not account for a large fraction of the variation in real activity either (at least at the business cycle frequency and over the sample considered here). As such, accounting for oil supply shocks should not alter the benchmark results, and it does not. ${ }^{29}$ For the productivity variable the results associated with the augmented model show larger positive effects after a resource activity shock, and larger negative effects after a commodity price shock. Only for the response in productivity after a resource activity shock is the difference between the two significant (on impact and after 5-6 quarters). As all the other responses are basically unchanged, the difference between the benchmark model and the augmented model in terms of productivity responses are likely a result of changes in the loading vector associated with the productivity variable. Thus, when global oil production is controlled for, the loading on the domestic resource factor becomes higher. This is confirmed by looking at the estimation results. While most of the other loadings remain constant, productivity's loading on the resource activity factor increases significantly. In economic terms we interpret this as a confirmation of the importance and identification of the resource activity shock: As described in Section 2, we can interpret the resource activity shock as a windfall gain associated with the discovery of new resources. By controlling for global oil supply we are able to (potentially) better identify the Norwegian specific effect on

\footnotetext{
${ }^{29}$ Consistent with the oil market literature cited above, we find that the oil market supply shock explains less than 5 percent of the variation in the real price of oil, and in most cases even less of the variation in the Norwegian macro variables.
} 
Figure 14. Norway: Controlling for global oil supply shocks. Resource gifts, commodity price shocks, and domestic responses

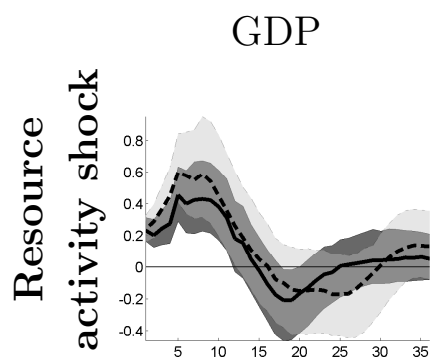

Productivity

Employment Real exchange rate
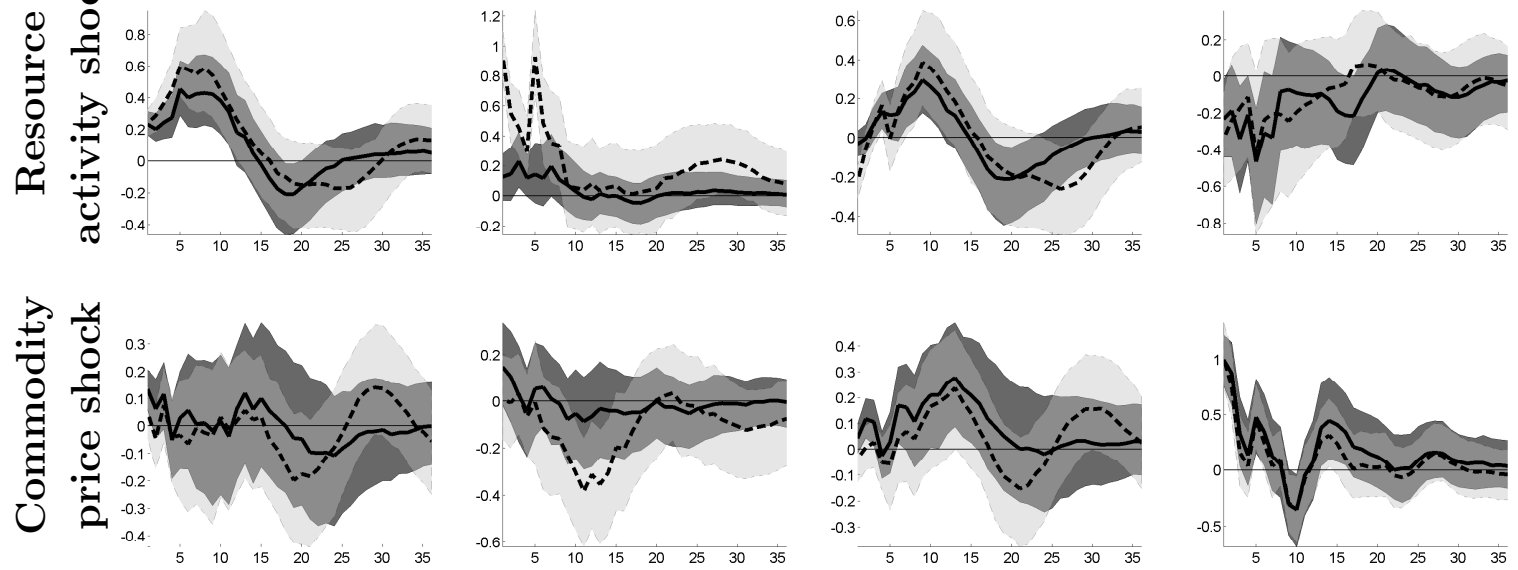

Note: See the note to Figure 12

productivity after this shock. 


\section{Appendix D The Gibbs sampling approach}

Below we describe some details of the estimation of the model described briefly in Section 3.3. For convenience, we repeat some notation: $\tilde{y}_{T}=\left[y_{1}, \cdots, y_{T}\right]^{\prime}, \tilde{f}_{T}=\left[f_{1}, \cdots, f_{T}\right]^{\prime}$, $H=\left[\lambda_{0}, \cdots, \lambda_{s}\right]$, and $p_{i}=\left[\rho_{1, i}, \cdots, \rho_{l, i}\right]$ for $i=1, \cdots, N$, Bayesian estimation of the state space model is based on Gibbs simulation, where the following three steps are iterated until convergence is achieved:

Step 1: Conditional on the data $\left(\tilde{y}_{T}\right)$ and all the parameters of the model, generate $\tilde{f}_{T}$ Step 2: Conditional on $\tilde{f}_{T}$, generate $\beta$ and $Q$

Step 3: Conditional on $\tilde{f}_{T}$, and data for the i-th variable $\left(\tilde{y}_{T, i}\right)$, generate $H_{i}, R_{i}$ and $p_{i}$ for $i=1, \cdots, N$

Below we describe the three steps in more detail. The exposition follows Kim and Nelson (1999) closely, and we refer to their book for details. We start by rewriting the state space model defined in equation 10 and 11 as:

$$
y_{t}=\Lambda F_{t}+\epsilon_{t}
$$

and

$$
F_{t}=A F_{t-1}+e_{t}
$$

where $F_{t}=\left[f_{t}^{\prime}, \cdots, f_{t-h}^{\prime}\right]^{\prime}, e_{t}=G u_{t}$, with $u_{t} \sim$ i.i.d.N $(0, Q)$ and:

$$
A=\left(\begin{array}{cccc}
\phi_{1} & \phi_{2} & \cdots & \phi_{h} \\
I_{q} & 0 & \cdots & 0 \\
0 & I_{q} & \ddots & \vdots \\
0 & 0 & I_{q} & 0
\end{array}\right), \quad G=\left(\begin{array}{c}
I_{q} \\
0 \\
\vdots \\
0
\end{array}\right), \quad \Lambda=\left(\begin{array}{ll}
H & 0_{N, h-s}
\end{array}\right)
$$

Note that $h>s$ in our application.

We also allow for serially correlated idiosyncratic errors. In particular, we consider the case where $\epsilon_{t, i}$, for $i=1, \cdots, N$, follows independent $\mathrm{AR}(\mathrm{l})$ processes:

$$
\epsilon_{t, i}=p_{i} E_{t, i}+\omega_{t, i}
$$

where $\omega_{t, i}$ is the $\operatorname{AR}(\mathrm{l})$ residuals with $\omega_{t, i} \sim$ i.i.d.N $\left(0, \sigma_{i}^{2}\right)$. I.e.:

$$
R=\left[\begin{array}{cccc}
\sigma_{1}^{2} & 0 & \cdots & 0 \\
0 & \sigma_{2}^{2} & \ddots & 0 \\
\vdots & \ddots & \ddots & \vdots \\
0 & \cdots & \cdots & \sigma_{N}^{2}
\end{array}\right]
$$

and $E_{t, i}=\left[\epsilon_{t-1, i}, \cdots, \epsilon_{t-l, i}\right]^{\prime}$.

\section{D.0.1 Step 1: $\tilde{f}_{T} \mid \tilde{y}_{T}, \Lambda, A, R, Q, p$}

We employ Carter and Kohn's multimove Gibbs sampling approach (see Carter and Kohn (1994)). Because the state space model given in equations 17 and 18 is linear and Gaussian, the distribution of $F_{T}$ given $\tilde{y}_{T}$ and that of $F_{t}$ given $F_{t+1}$ and $\tilde{y}_{t}$ for $t=T-1, \cdots, 1$ are also Gaussian:

$$
F_{T} \mid \tilde{y}_{T} \sim N\left(F_{T \mid T}, P_{T \mid T}\right)
$$




$$
F_{t} \mid \tilde{y}_{t}, F_{t+1} \sim N\left(F_{t \mid t, F_{t+1}}, P_{t \mid t, F_{t+1}}\right), \quad t=T-1, T-2, \cdots, 1
$$

where

$$
\begin{aligned}
F_{T \mid T} & =E\left(F_{T} \mid \tilde{y}_{T}\right) \\
P_{T \mid T} & =\operatorname{Cov}\left(F_{T} \mid \tilde{y}_{T}\right) \\
F_{t \mid t, F_{t+1}} & =E\left(F_{t} \mid \tilde{y}_{t}, F_{t+1}\right)=E\left(F_{t} \mid F_{t \mid t}, F_{t \mid t+1}\right) \\
P_{t \mid t, F_{t+1}} & =\operatorname{Cov}\left(F_{t} \mid \tilde{y}_{t}, F_{t+1}\right)=\operatorname{Cov}\left(F_{t} \mid F_{t \mid t}, F_{t \mid t+1}\right)
\end{aligned}
$$

Given $F_{0 \mid 0}$ and $P_{0 \mid 0}$, we obtain $F_{T \mid T}$ and $P_{T \mid T}$ from the last iteration of the Gaussian Kalman filter:

$$
\begin{aligned}
F_{t \mid t-1} & =A F_{t-1 \mid t-1} \\
P_{t \mid t-1} & =A P_{t-1 \mid t-1} A^{\prime}+G Q G^{\prime} \\
K_{t} & =P_{t \mid t-1} \Lambda^{\prime}\left(\Lambda P_{t \mid t-1} \Lambda^{\prime}+R\right)^{-1} \\
F_{t \mid t} & =F_{t \mid t-1}+K_{t}\left(y_{t}-\Lambda F_{t \mid t-1}\right) \\
P_{t \mid t} & =P_{t \mid t-1}-K_{t} \Lambda P_{t \mid t-1}
\end{aligned}
$$

I.e., at $t=T$, equation 31 and 32 above, together with equation 22 , is used to draw $F_{T \mid T}$.

We draw $F_{t \mid t, F_{t+1}}$ for $t=T-1, T-2, \cdots, 1$ based on 23, where $F_{t \mid t, F_{t+1}}$ and $P_{t \mid t, F_{t+1}}$ are generated from the following updating equations:

$$
\begin{aligned}
& F_{t \mid t, F_{t+1}}=E\left(F_{t} \mid F_{t \mid t}, F_{t \mid t+1}\right) \\
& =F_{t \mid t}+P_{t \mid t}^{\prime} A\left(A P_{t \mid t} A^{\prime}+G Q G^{\prime}\right)^{-1}\left(F_{t+1}-A F_{t \mid t}\right) \\
& P_{t \mid t, F_{t+1}}=\operatorname{Cov}\left(F_{t} \mid F_{t \mid t}, F_{t \mid t+1}\right) \\
& =P_{t \mid t}+P_{t \mid t} A^{\prime}\left(A P_{t \mid t} A^{\prime}+G Q G^{\prime}\right) A P_{t \mid t}
\end{aligned}
$$

D.0.2 Step 2: $A, Q \mid \tilde{y}_{T}, \tilde{f}_{T}, \Lambda, R, p$

Conditional on $\tilde{f}_{T}$, equation 18 is independent of the rest of the model, and the distribution of $\mathrm{A}$ and $\mathrm{Q}$ are independent of the rest of the parameters of the model, as well as the data.

By abusing notation, we put the transition equation in SUR form and define:

$$
y=X \beta+\epsilon
$$

where $y=\left[f_{1}, \cdots, f_{T}\right]^{\prime}, X=\left[X_{1}, \cdots, X_{T}\right]^{\prime}, \epsilon=\left[\epsilon_{1}, \cdots, \epsilon_{T}\right]^{\prime}$ and $\beta=\left[\beta_{1}, \cdots, \beta_{q}\right]^{\prime}$, with $\beta_{k}=\left[\phi_{1, k}, \cdots, \phi_{h, k}\right]$ for $k=1, \cdots, q$. Further,

$$
X_{t}=\left(\begin{array}{cccc}
x_{t, 1} & 0 & \cdots & 0 \\
0 & x_{t, 2} & \ddots & \vdots \\
\vdots & \ddots & \ddots & \vdots \\
0 & \cdots & \cdots & x_{t, q}
\end{array}\right)
$$


with $x_{t, k}=\left[f_{t-1}^{\prime}, \cdots, f_{t-h}^{\prime}\right]$. Finally, $\epsilon \sim$ i.i.d. $N\left(0, I_{q} \otimes Q\right){ }^{30}$

To simulate $\beta$ and $\mathrm{Q}$, we employ the independent Normal-Whishart prior:

$$
p(\beta, Q)=p(\beta) p\left(Q^{-1}\right)
$$

where

$$
\begin{gathered}
p(\beta)=f_{N}\left(\beta \mid \underline{\beta}, \underline{V}_{\beta}\right) \\
p\left(Q^{-1}\right)=f_{W}\left(Q^{-1} \mid \underline{v}_{Q}, \underline{Q}^{-1}\right)
\end{gathered}
$$

The conditional posterior of $\beta$ is:

$$
\beta \mid y, Q^{-1} \sim N\left(\bar{\beta}, \bar{V}_{\beta}\right)_{I[s(\beta)]}
$$

with

$$
\bar{V}_{\beta}=\left(\underline{V}_{\beta}^{-1}+\sum_{t=1}^{T} X_{t}^{\prime} Q^{-1} X_{t}\right)^{-1}
$$

and

$$
\bar{\beta}=\bar{V}_{\beta}\left(\underline{V}_{\beta}^{-1} \underline{\beta}+\sum_{t=1}^{T} X_{t}^{\prime} Q^{-1} y_{t}\right)
$$

$I[s(\beta)]$ is an indicator function used to denote that the roots of $\beta$ lie outside the unit circle.

The conditional posterior of $Q^{-1}$ is:

$$
Q^{-1} \mid y, \beta \sim W\left(\bar{v}_{Q}, \bar{Q}^{-1}\right)
$$

with

$$
\bar{v}_{Q}=\underline{v}_{Q}+T
$$

and

$$
\bar{Q}=\underline{Q}+\sum_{t=1}^{T}\left(y_{t}-X_{t} \beta\right)\left(y_{t}-X_{t} \beta\right)^{\prime}
$$

D.0.3 Step 3: $\Lambda, R, p \mid \tilde{y}_{T}, \tilde{f}_{T}, A, Q$

Conditional on $\tilde{f}_{T}$, and given our assumption of $\mathrm{R}$ being diagonal, equation 17 result in $\mathrm{N}$ independent regression models.

However, to take into account serially correlated idiosyncratic errors, and still employ standard Bayesian techniques, we need to transform equation 17 slightly.

Thus, for $i=1, \cdots, N$, conditional on $\mathrm{p}$, and with $l=1$, we can rewrite equation 17 as:

$$
y_{t, i}^{*}=\Lambda_{i} F_{t}^{*}+\omega_{t, i}
$$

with $y_{t, i}^{*}=y_{t, i}-p_{1, i} y_{t-1, i}$, and $F_{t}^{*}=F_{t}-p_{1, i} F_{t-1}$, and $\Lambda_{i}$ being the i-th row of $\Lambda$.

${ }^{30}$ With the transition equation specified in SUR form it becomes easy to adjust the VAR(h) model such that different regressors enter the q equations of the $\operatorname{VAR}(\mathrm{h})$. 
From 45 we can then simulate the parameters $\Lambda_{i}$ and $R_{i, i}=\sigma_{i}^{2}=\frac{1}{h_{i}}$ using standard independent Normal-Gamma priors (for notational convenience we drop the subscript i from the expressions below): ${ }^{31}$

$$
p(\Lambda, h)=p(\Lambda) p(h)
$$

where

$$
\begin{aligned}
& p(\Lambda)=f_{N}\left(\Lambda \mid \underline{\Lambda}, \underline{V}_{\Lambda}\right) \\
& p(h)=f_{G}\left(h \mid \underline{s}^{-2}, \underline{v}_{h}\right)
\end{aligned}
$$

The conditional posterior of $\Lambda$ is:

$$
\Lambda \mid \tilde{y}, h, p \sim N\left(\bar{\Lambda}, \bar{V}_{\Lambda}\right)
$$

with;

$$
\bar{V}_{\Lambda}=\left(\underline{V}_{\Lambda}^{-1}+h \sum_{t=1}^{T} F_{t}^{*^{\prime}} F_{t}^{*}\right)^{-1}
$$

and

$$
\bar{\Lambda}=\bar{V}_{\Lambda}\left(\underline{V}_{\Lambda}^{-1} \underline{\Lambda}+h \sum_{t=1}^{T} F_{t}^{*^{\prime}} y_{t}^{*}\right)
$$

The conditional posterior for $h$ is:

$$
h \mid \tilde{y}, \Lambda, p \sim G\left(\bar{v}_{h}, \bar{s}^{-2}\right)
$$

with

$$
\bar{v}_{h}=\underline{v}_{h}+T
$$

and

$$
\bar{s}=\frac{\sum_{t=1}^{T}\left(y_{t}^{*}-\Lambda F_{t}^{*}\right)^{\prime}\left(y_{t}^{*}-\Lambda F_{t}^{*}\right)+\underline{v}_{h} \underline{s}^{2}}{\bar{v}_{h}}
$$

Finally, conditional on $\Lambda$ and h, the posterior of p depends upon its prior, which we assume is a multivariate Normal, i.e.:

$$
p(p)=f_{N}\left(p \mid \underline{p}, \underline{V}_{p}\right)
$$

Accordingly, the conditional posterior for $\mathrm{p}$ is:

$$
p \mid \tilde{y}, \Lambda, h \sim N\left(\bar{p}, \bar{V}_{p}\right)_{I[s(p)]}
$$

with

$$
\bar{V}_{p}=\left(\underline{V}_{p}^{-1}+h \sum_{t=1}^{T} E_{t}^{\prime} E_{t}\right)^{-1}
$$

and

$$
\bar{p}=\bar{V}_{p}\left(\underline{V}_{p}^{-1} \underline{p}+h \sum_{t=1}^{T} E_{t}^{\prime} \epsilon_{t}\right)
$$

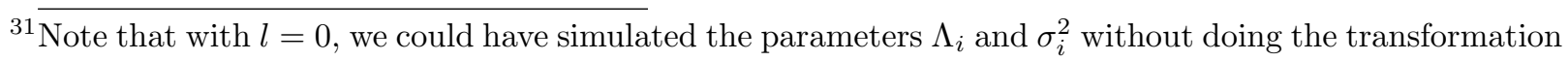
of variables described above. 


\section{D.0.4 Prior specifications and initial values}

The Benchmark model is estimated using two-step parameter estimates (see Section 3.3) as priors. We label these estimates OLS. In particular, for equations 37 and 38 we set $\underline{\beta}=\beta^{O L S}, \underline{V}^{\beta}=V_{\beta}^{O L S} \times 3, \underline{Q}=Q^{O L S}$ and $\underline{v}_{Q}=10$.

For equations 47,48 and 55 we set $\underline{v}_{h}=10, \underline{s}^{2}=s^{2, O L S}, \underline{\Lambda}=\left[\lambda_{0}^{O L S}: 0_{N, h-s-1}\right]$ and $\underline{V}^{\Lambda}=\left[\left(I_{s} \times 3\right) \otimes V_{\lambda_{0}^{O L S}}\right] . \underline{p}=0$, and $\underline{V}^{p}=0.5$.

In sum, these priors are reasonable uninformative, but still proper. We have also experimented with other prior specifications, e.g. using Minnesota style prior for the transition equation parameters, and setting $\underline{\Lambda}=0$. This yields similar results as the once reported in the main text. However, the variables in our sample display very different unconditional volatilities. The prior specification should accommodate this feature.

The Gibbs sampler is initialized using parameter values derived from the two-step estimation procedure. Parameters not derived in the two-step estimation (i.e. $p$ and $\left.\lambda_{1}, \cdots, \lambda_{s}\right)$ are set to 0 .

In this model, a subtle issue arises for the $t=0$ observations (i.e. lags of the dynamic factors and the idiosyncratic errors at time $t=1$ ). However, since we assume stationary errors in this model, the treatment of initial conditions is of less importance. Accordingly, we follow common practice and work with the likelihood based on data from $t=h+$ $1, \cdots, T$. 
Centre for Applied Macro - and Petroleum economics (CAMP)

will bring together economists working on applied macroeconomic issues, with special emphasis on petroleum economics.

BI Norwegian Business School

Centre for Applied Macro - Petroleum economics (CAMP)

N-0442 Oslo

http://www.bi.no/camp 